\title{
Tezners Schriften zur Verwaltungsrechtspflege in Österreich und ihre Impulse für den modernen Gerichtsbegriff
}

\author{
Tezner's Writings about Administrative Jurisdiction in Austria \\ and their Impact on the Modern Definition of a Court
}

Tezner's plea against the misunderstanding of absolutistic reforms, as in the context of the rule of law, demonstrates continuities regarding administrative jurisdiction in the history of courts in Austria. The organisational principle of extending benches of judges by including judicial councillors survived all Josephinian reforms. Judicial councillors represented the sovereign's interests. Studying the decisions of the Supreme Justice Office (Oberste Justizstelle), Tezner found that it provided rather generously for these interests.

Keywords: Administrative Jurisdiction - TEZNER, Friedrich

\section{Einführung:}

\section{Historische versus moderne Verwaltungsrechtspflege?}

Für die ehrenvolle Einladung auf der Akademietagung "Gerichtsvielfalt in Wien“ zu sprechen danke ich herzlich und möchte gleich medias in res - mit der Auseinandersetzung Karl Freiherr von Lemayers mit dem von Tezner gesammelten Quellenmaterialien beginnen: Tezners Terminologie des „verwaltungsgerichtlichen Rechtsschutzes" in seinen historischen Abhandlungen der Verwaltungsrechtspflege in Österreich sei nicht gerechtfertigt, da nach seiner, Lemayers zum 25. Bestehen des Verwaltungsgerichtshofes geäußerten Auffassung, vor der zweiten Hälfte des 19. Jahrhunderts keine Verwaltungsgerichtsbarkeit bestand. ${ }^{1}$

\footnotetext{
${ }^{1}$ LEMAYER, Begriff des Rechtsschutzes 1. Für die Zuarbeit mit Quellen und Literatur danke ich Franziska Neugebauer und Donata Zehner.
}

Im Kontext der österreichischen Justizgeschichte haben die Impulse für den modernen Gerichtsbegriff aus Tezners Schriften zur Verwaltungsrechtspflege in Österreich eine doppelte Begrifflichkeit der Verwaltungsrechtspflege zu beachten. Während der subjektive Individualrechtsschutz gegen Hoheitsakte den modernen Verwaltungsprozess prägt, gehen Tezners Schriften und namentlich seine zentrale Darstellung "Landesfürstliche Verwaltungsrechtspflege in Österreich" (1898/1902) von einer objektiven Begrifflichkeit der Verwaltungsrechtspflege aus, welche die Justizgeschichte in der monarchischen Union der habsburgischen Staaten und im theresianischen Absolutismus prägt. Die Wirkmächtigkeit der historischen Verwaltungsrechtspflege für die österreichische Justizgeschichte allgemein und für die Entstehungsgeschichte des modernen Gerichtsbegriff ergibt sich gerade aus dem grundlegenden Organisationsprinzip der Justizbeteiligung des österreichischen Kammerwesens für die Ausbildung der österreichischen Verwaltungsrechtspflege in 
Tezners Werken. Der nachfolgende Beitrag widmet sich nach der Organisationspolitik der monarchischen Union der habsburgischen Staaten als Grundlage für den habsburgische Aufstieg zur europäischen Großmacht (II.) der vergleichend historischen Einordnung des österreichischen Kammerwesens in die Justiztheorie des Absolutismus (III.), bevor er sich gegen das „rechtsstaatliche“ Missverständnis absolutistischer Verwaltungs- und Justizreformen (IV.) wendet.

Friedrich Tezner (Geburtsname Tänzerles²/Tänzlers ${ }^{3}$ ) wurde am 11. Juni 1856 in Beraun [Beroun] in Böhmen als Kind des jüdischen Religionslehrers Leopold Tänzerles/Tänzlers geboren. ${ }^{4}$ Seine Familie mit mehreren Geschwistern - mindestens zwei Brüder sind bekannt - zog nach Böhmisch Leipa [Česká Lípa], wo Tezner das Gymnasium des Augustinerklosters besuchte. ${ }^{5}$ Nach dem Rückzug 1870 nach Wien beendete Tezner dort seine Mittelschulzeit und legte am akademischen Gymnasium die Maturaprüfung ab. ${ }^{6}$ Zum Wintersemester 1874/1875 schrieb er sich zum Studium der Rechtswissenschaften an der Universität Wien ein.7 1878/1879 legte Tezner die Rigorosen sehr erfolgreich ab. ${ }^{8}$ Nach dem Eintritt in die Gerichtspraxis am 19. August 1878 waren Tezners Stationen das Bezirksgericht Innere Stadt Wien, das Landesgericht für Zivilrechtssachen und das Landesgericht für Strafsachen, abschließend das Bezirksgericht Leopoldstadt. ${ }^{9}$ Eine richterliche Laufbahn, sowie der Eintritt in die allgemeine staatliche Verwaltung blieben ihm vermutlich aufgrund seines jüdi-

\footnotetext{
${ }^{2}$ KREMZOW, Friedrich Tezner 26.

${ }^{3}$ OleCHOWSKI, Der österreichische Verwaltungsgerichtshof 39; DERS. Entwicklung allgemeiner Grundsätze des Verwaltungsverfahrens 13-40.

${ }^{4}$ KREMZOW, Friedrich Tezner 26.

${ }^{5}$ Ebd.

${ }^{6}$ Ebd. 27.

${ }^{7}$ Ebd.

${ }^{8}$ Ebd. 28.

${ }^{9}$ Ebd.
}

schen Familiennamens verwehrt. ${ }^{10}$ Die Promotion Tezners zum Doktor der Rechtswissenschaften erfolgte am 14. November 1879.11 Anschließend ließ Tezner sich in die Liste der Rechtsanwaltsanwärter eintragen und arbeitete bis 1882 als Rechtsanwalt. ${ }^{12}$ Im selben Jahr wurde Tezners Antrag auf Namensänderung von Tänzerles/Tänzlers zu Tezner stattgegeben, was wohl der kurz darauf erfolgten Anstellung bei der Kanzlei des Hof- und Gerichtsadvokaten Josef Kopp, zu dessen Juniorpartner er aufstieg, förderlich war. ${ }^{13}$ In der Kanzlei des Josef Kopp war Tezner bis zum Sommer 1889 tätig. ${ }^{14}$ Kopp war unter anderem Reichsratsabgeordneter. Am 1. Januar 1891 begann Tezner in der Stellung eines Sekretärs ${ }^{15} /$ Rechtskonsulenten $^{16}$ bei der neuen Wiener Sparkasse zu arbeiten und kehrte nach Wien zurück. In dieser Zeit habilitierte er sich an der Universität Wien für Verfassungsund Verwaltungsrecht.

Am 13. Juni beantragte Tezner die Lehrberechtigung für das Fach österreichisches Verwaltungsrecht bei der rechts- und staatswissenschaftlichen Universität Wien, die ihm am 14. Juli 1892 erteilt wurde. ${ }^{17}$ Im Sommersemester 1893 hielt er daraufhin zum ersten Mal die zweistündige Vorlesung „Österreichisches Gemeinderecht mit Berücksichtigung des Wiener Gemeindestatuts“, im folgenden Wintersemester die Vorlesung "Administratives Verfahren und Verwaltungsgerichtsbarkeit“. ${ }^{18}$ Am 21. März 1895 wurde Tezner zum Prüfungskommissär für allgemeines und österreichisches Staatsrecht sowie für Verwaltungslehre und österreichisches Verwaltungsrecht im Rahmen der Staats-

\footnotetext{
${ }^{10}$ Ebd.

${ }^{11}$ Ebd.

12 Ebd. $28 \mathrm{f}$.

13 Ebd. 29.

14 Ebd. 30.

${ }^{15}$ Ebd. 31.

16 SCHENK, Friedrich Tezner 185.

17 Ebd. 31f.

${ }^{18}$ Ebd. 32.
} 
prüfung. ${ }^{19}$ Im August 1900 wurde Tezner der Titel des außerordentlichen Universitätsprofessors verliehen, er wurde aber nie an die Universität berufen. ${ }^{20}$

$\mathrm{Zu}$ seinen bedeutendsten Werken gehören das „Handbuch des österreichischen Administrativverfahrens", Wien 1896, welches "für das deutsche Sprachgebiet die erste systematische Bearbeitung des Verwaltungsverfahrens [ist] “21 und „Zur Lehre von dem freien Ermessen der Verwaltungsbehörden als Grund der Zuständigkeit der Verwaltungsgerichte“, Wien 1888, „Der Kaiser", Wien 1909, "Die Volksvertretung", Wien 1912, „Die Wandlungen der österreichischungarischen Reichsidee“, Wien 1905, "Ausgleichsrecht und Ausgleichspolitik", Wien 1907. 1925 erschien das große Werk „Die rechtsbildende Funktion der österreichischen Verwaltungsrechtsprechung“, I. Teil, „Rechtslogik und Rechtswirklichkeit“, II. Teil, „Die Rechtsquellen des österreichischen Verwaltungsrechtes", III. Teil, „Die Ordnung der Zuständigkeiten der österreichischen Verwaltungsbehörden", IV. Teil, „Das österreichische Administrativverfahren“.22 Seine Werke beeinflussten die neuen Gesetze über das Verwaltungsverfahren (1925): „Ohne ihn [Tezner] wären diese Gesetze nicht so bald und gewiß nicht so gut zustande gekommen." ${ }^{23}$ 1907 wurde Tezner zunächst, durch die Berufung durch Freiherr von Beck, Rat am österreichischen Verwaltungsgerichtshof. 1921 stieg er zum Senatspräsidenten auf. Hochangesehen verstarb Tezner am 13. Juni 1925 in Wien im Alter von 69 Jahren. „Die außerordentliche Kraft seiner Persönlichkeit, seine hervorragenden Eigenschaften als Mensch, Gelehrter und Richter

\footnotetext{
19 Vgl. ebd. 33.

${ }^{20}$ Ebd. 34.

${ }^{21}$ SCHENK, Friedrich Tezner 185.

${ }^{22} \mathrm{Zu}$ dieser Aufzählung vgl. LEHNE, Geschichte der Verwaltungsstreitsache 27, Anm. 6.

${ }^{23}$ SCHENK Friedrich Tezner 185. Vgl. auch SCHWÄRLER, Friedrich Tezner 242-247.
}

spiegeln sich in bewegender Weise in den zahlreichen Nachrufen, von Hans Kelsen im ,Neuen Wiener Tagblatt' vom 14. Juni 1925, Rudolf Herrnritt in der ,Neuen Freien Presse' vom gleichen Tage, Viktor Fuchs in der ,Reichspost' vom 16. Juni 1925 und in der ,Arbeiter-Zeitung' vom 14. Juni 1925. Besonders eindrucksvoll ist der Gedenkartikel ,Der österreichische Richter und Gelehrte Friedrich Tezner' von dem k.k. Justizminister a.D. Dr. Josef Schenk im österreichischen Verwaltungsblatt, 6 (1935) 185-188“. ${ }^{24}$

\section{Organisationspolitik der monarchischen Union der habsburgischen Staaten als Grundlage für den habsburgischen Aufstieg zur europäischen Großmacht}

\section{Territoriale Diversität der habsburgischen Herrschaftsmasse und katholische Uniformität des habsburgischen Kaisertums}

Bereits im 16. Jahrhundert hatte das „Haus Österreich", 25 seit 1438 ununterbrochen im Besitz der (römisch-deutschen) Kaiserwürde, ${ }^{26} \mathrm{zu}$ den beiden Teilen des Erzherzogtums ${ }^{27}$ Österreich

\footnotetext{
${ }^{24}$ LEHNE, Geschichte der Verwaltungsstreitsache 27, Anm. 6.

${ }^{25}$ Zum Begriff „Haus Österreich“ vgl. NIEDERSTÄTTER, Herrschaft Österreich 168; 1493 verbindet Maximilian I. das Haus Österreich und die burgundischen Herrschaft (Haus Burgund) in landesfürstlicher Personalunion (BRAUNEDER, Verfassungsgeschichte 69).

${ }^{26}$ WINKLER, Langer Weg nach Westen 123.

27 Zur Anlehnung der Sonderrechte im Privilegium maius (Unteilbarkeit der Länder, automatische Primogenitur, Exemtion der Gerichtsbarkeit und Herrschaftssymbole) an den Kurfürstenstatus im Heiligen Römischen Reich vgl. BALTL, KOCHER, Rechtsgeschichte $84 \mathrm{ff}$.
} 
(unter und ob der Enns), ${ }^{28}$ zu Innerösterreich mit Steiermark, Kärnten und Krain, zur Grafschaft Tirol und zu den vorderösterreichischen Herrschaftsgebieten zwischen Vorarlberg und dem Breisgau noch das österreichische Küstenland (Triest [Trieste] und Görz [Gorizia]), das König- und Kurfürstentum Böhmen ${ }^{29}$ und die ungarische Krone ${ }^{30}$ gewinnen können. Im Westfälischen Frieden ging mit den elsässischen Besitzungen zwar "die Landbrücke zu den spanischen Besitzungen in Oberitalien und Burgund verloren", ${ }^{31}$ doch die Vorlande (vorderösterreichische Besitzungen) boten einen bedeutsamen Zugang zum gesamten "Südwesten des Reiches". ${ }^{32}$ Bei dieser territorialen Diversität der habsburgischen Herrschaftsmasse war es die katholische Uniformität des habsburgischen Kaisertums, ${ }^{33}$ welche die Einheit des „Gesamt-

\footnotetext{
${ }^{28}$ Bereits im 13. Jahrhundert wird zwischen dem Land ob der Enns und dem Land unter der Enns unterschieden, die zusammen bis 1806 „ein Reichslehen“ bilden (BRAUNEDER, Verfassungsgeschichte 27). Diese Gebiete sind mit den Bundesländern Ober- und Niederösterreich vergleichbar (BRAUNEDER, Verfassungsgeschichte 19).

${ }^{29} 1526$ erwerben die Habsburger Böhmen, Mähren, Schlesien und die Lausitz (BRAUNEDER, Verfassungsgeschichte 71); zur Bedeutung des Habsburgerreiches "durch den Erwerb der Herrschaft in den Ländern der Wenzelskrone und in denen der Stefanskrone 1526" vgl. HOKE, Rechtsgeschichte 196.

30 1526/27 erwerben die Habsburger Oberungarn (= die Slowakei und das heutige Burgenland) und Teile Kroatiens, während Kernungarn mit Ofen als Hauptstadt osmanisch (BRAUNEDER, Verfassungsgeschichte 71) und Siebenbürgen ein dem osmanischen Reich tributpflichtiges Fürstentum wird vgl. auch HOKE, Rechtsgeschichte 197.

31 SCHIEDER WAGNER, , Handbuch 396.

32 Ebd. 396.

${ }^{33}$ Kaiser Leopold hatte sich auf dem westfälischen Friedenskongress den allgemeinen Regelungen der Religionsfragen für seine Lande verweigert (SCHIEDER, WAGNER, Handbuch 396). (a.A.: Leopold I. „als Wahrer [...] des Westfälischen Frieden“ trotz "seiner ausgeprägten persönlichen Katholizität und im Gegensatz zu seiner gegenreformatorischen Religionspolitik", SchINDLING, Leopold I. 171.) 1654 wird die
}

staates" ausmachte. Die „protestantischen Untertanen wurden registriert und systematisch einer katholischen Reform unterworfen", nur in einigen schlesischen Fürstentümern und Städten wurden Protestanten geduldet. ${ }^{34}$ „Herrschaftsträger ist allein der Monarch", als Inhaber der jeweiligen landesfürstlichen Rechte, ${ }^{35}$ ohne dass die Summe eine eigene Rechtspersönlichkeit als "gemeinsamer Landesfürst" gewesen wäre: die Institutionalisierung der Monarchischen Union (indivisibiliter ac inseparabiliter) ${ }^{36}$ durch einheitliche Primogeniturerbfolge im Mannesstamm bei subsidiärem Erbrecht der Tochter in der Pragmatischen Sanktion $1713^{37}$ belässt die unterschiedlichen Nachfolgeregelungen der verschiedenen Landesherrschaften. ${ }^{38}$ Interessanterweise

Reichshofratsordnung im Sinne der katholischkaiserlichen Machtvollkommenheit revidiert. Die einheitliche Primogenitur gilt für Alt-Österreich ab dem privilegium maius (vgl. BALTL, KOCHER, Rechtsgeschichte 85), die Neuheit der Pragmatischen Sanktion bezieht sich auf die weibliche Thronfolge.

${ }^{34}$ SCHIEDER, WAGNER, Handbuch 396.

35 Als König von Böhmen ist der habsburgische Monarch Reichsfürst (zur Stellung des Königs von Böhmen als Reichsfürst seit dem 12. Jahrhundert vgl. WÜNSCH, Deutsche und Slawen 14), sogar Kurfürst (vgl. CoRnOvA, Unterhaltungen 2, 31), als König von Ungarn vollsouveräner Monarch (zur Stellung als Reichsfürst, Kurfürst und vollsouveräner Monarch vgl. BRAUNEDER, Verfassungsgeschichte 73). Das Zusammenwirken von Kaiseramt und Stellung als Landesfürst lässt sich auch bei Tauschgeschäften von Landmassen beobachten: So konnte Ferdinand II. mit der ihm als Kaiser anheimgefallenen Oberpfalz als Landesfürst das 1620 an Bayern verpfändete Land ob der Enns (vgl. AlBRECHT, Ferdinand II. 132) zurückgewinnen

${ }^{36}$ Art. II der pragmatischen Sanktion im ungarischen Gesetz von 1723 in lateinischer Fassung: TURBA, Pragmatische Sanktion 181.

${ }^{37}$ KotUlLA, Verfassungsgeschichte 248, Anm. 979.

${ }^{38}$ Während in Böhmen und Ungarn zunächst das Wahlrecht gilt, sich ab 1620 (Böhmen) bzw. 1687 (Ungarn) die Erbfolge nach Primogenitur durchsetzt, gilt in den deutschen Erbländern Erbrecht ohne Primogenitur (BRAUNEDER Verfassungsgeschichte 73; vgl. zu Böhmen und Ungarn auch KOTULLA, Verfassungsgeschichte 248, Rz. 977). Die bedeutendste inhaltliche 
bleibt der habsburgische Monarch bis 1804 ohne eigenen Titel, ${ }^{39}$ die römisch-deutsche Kaiserwürde genügte als stellvertretendes Symbol der Einheit der habsburgischen Ländergruppe. Aus der Kaiserwürde lässt sich auch die außenpolitische Ebenbürtigkeit mit der hohen Pforte ableiten.

\section{Schlaglichter der Geschichte österreichischer Behördenorganisation}

Gemäß den Brüsseler Vereinbarungen von 1522 gehen die spanischen und niederländischen Gebiete an Karl V., während Ferdinand I. „die habsburgischen Alpen- und Donauländer" erhält, weshalb auch von Erbteilung die Rede ist. ${ }^{40}$ Ziel Ferdinands I. (1503-1564) ist „die Territorialisierung durch die Schaffung eines neuen landesfürstlichen Behördenapparats". ${ }^{41}$ Es gelingt ihm, eine Hofstaatsordnung $\mathrm{zu}$ schaffen, die zum Teil bis 1848, jedenfalls bis Mitte des 18. Jahrhundert Gültigkeit hat. ${ }^{42}$

Das katholische Kaisertum Leopolds I. (1658-1705) schafft in der Doppelkonfrontation ${ }^{43}$ zwischen Frankreich im Westen (Devolutionskriege Ludwigs XIV.) und dem Osmanischen Reich im Osten (Türken vor Wien) eine erste absolutistische Konzentration der monarchischen Union der habsburgischen Staaten. Der weiteren Sicherung der Macht Österreichs die-

Neuerung der Pragmatischen Sanktion 1713 ist die subsidiäre weibliche Erbfolge, die Ungarn bis dahin nicht kannte; zur subsidiären weiblichen Erbfolge vgl. SCHIEDER, WAGNER, Handbuch 431f.

${ }^{39}$ Von Ferdinand II. stammt der Plan, die österreichischen Territorien „zu einem ,Königreich Österreich” zusammenzufassen“ (BRAUNEDER, Verfassungsgeschichte 73).

${ }^{40}$ NiEDERSTÄTtER, Herrschaft Österreich 102; zur damit verbundenen Entwicklung der spanisch-niederländischen und österreichischen Linie vgl. SIMÁNYI, Ferdinand von Habsburg 59f; POHL, VOCELKA, Habsburger 121.

${ }^{41}$ NiEDERSTÄTtER, Herrschaft Österreich 103.

$42 \mathrm{Ebd}$.

${ }^{43}$ Vgl. SCHINDLING, Leopold I. 172. nen ein funktionierendes Bündnissystem und die Festlegung der Thronfolge. ${ }^{44}$ Karl VI. (1685-1740) bestimmt im Rahmen der Pragmatischen Sanktion die „Primogenitur im männlichen und weiblichen Stamme" ${ }^{45}$ wobei wie bei der spanischen Thronfolge „innerhalb einer Linie des Frauenstammes" Männervorzug gilt. ${ }^{46}$ Gleichzeitig geht sie „von der Unteilbarkeit (indivisibilitas) und Untrennbarkeit (inseparabilitas) der habsburgischen Länder aus" ${ }^{47}$ Die Regelung gilt als "Grundgesetz aller habsburgischen Erblande“ und dient der "untrennbaren Union dieser Länder" ${ }^{48}$ Folglich trägt sie zur Entwicklung einer österreichischen Großmacht bei. ${ }^{49}$

Karls Regierung war mit der Durchsetzung der Pragmatischen Sanktion innerhalb der habsburgischen Länder und dem Ringen um deren Akzeptanz bei den anderen europäischen Mächten absorbiert,50 Verwaltung und Militär wurden vernachlässigt. ${ }^{51}$ Auch wenn der Stellenwert des Reichsgedankens in seiner Zeit stark nachließ, war er der letzte Kaiser, zu dessen Politikkalkül neben der Wahrung habsburgischer Interessen auch eine aktive Reichspolitik gehörte. Sein Ausbau Wiens auf dem Höhepunkt des Barock ${ }^{52}$ spiegelt nicht nur den kaiserlichen Machtanspruch, sondern auch die beginnende deutliche "Trennung von Hof- und Staatsverwaltung "53 wider, auch wenn es nicht gelang, aus dem Nebeneinander der verschiedenen zentralen Be-

\footnotetext{
44 SCHIEder, WAgner, Handbuch 431.

45 BECKER, Pragmatische Sanktion 1865.

46 TURBA, Pragmatische Sanktion XI.

${ }^{47}$ BECKER, Pragmatische Sanktion 1865.

${ }^{48}$ SCHMIDT, Karl VI. 206.

${ }^{49} \mathrm{Ebd}$.

${ }^{50}$ Ebd.; SCHIEDER, WAGNER, Handbuch 432.

${ }^{51}$ BRAUBACH, Karl VI. 217.

52 So lässt er 1713, entsprechend seinem Gelöbnis, die Karlskirche nach den Plänen Fischer von Erlachs erbauen ebd. 217; zur Errichtung Stift Klosterneuburgs vgl. SCHMIDT, Karl VI. 214; zur Erweiterung der Hofburg vgl. BRAUBACH, Karl VI. 217.

${ }^{53}$ BUCHMANN, Wien 55.
} 
hörden eine effektive Staatsführung zu formen. ${ }^{54}$ Dies sollte seiner Tochter und Nachfolgerin Maria Theresia (1717-1780) vorbehalten sein. Als regierende Erzherzogin von Österreich und Königin u.a. von Ungarn (mit Kroatien) und Böhmen (1740-1780) war sie eine der prägendsten Gestalten des aufgeklärten Absolutismus. Unmittelbar nach Beginn ihrer Herrschaft war Maria Theresia mit dem Österreichischen Erbfolgekrieg konfrontiert. Wenn sie auch den größten Teil Schlesiens und die Grafschaft Glatz an Preußen verlor, ${ }^{55}$ gelang ihr für alle weiteren Habsburger Besitzungen ein Bestandsschutz und in der Folge eine umfassende Reformpolitik in der Staatsorganisation, im Justiz- und im Bildungswesen. Dem aufgeklärten Absolutismus entsprach die Minderung des Einflusses der Stände und partikularen Kräfte und die komplementäre Stärkung des Zentralstaates. 1765 erhob sie ihren Sohn Joseph II. (1741-1790) zum Mitregenten, dessen Absolutismus sich durch das rigorose Negieren partikularer Eigenständigkeiten pedantisch vom theresianischen Absolutismus unterschied. Die adligen Ständeversammlungen wurden zugunsten von Staatsbeamten eingeschränkt. Der josephinische Einheitsstaat, welcher den Untertanen $\mathrm{zu}$ ihrem eigenen Wohl bis ins allerkleinste Detail ${ }^{56}$ (Pfeffernüsse) Vorschriften machte, versuchte auch mittels Kunstpolitik den Untertanengeist poli-

\footnotetext{
${ }^{54}$ Vgl. BRAUBACH, Karl VI. 217.

${ }^{55}$ Außenpolitisch suchte Maria Theresia den Ausgleich mit Frankreich. Zum Verlust Schlesiens nach Ende des Siebenjährigen Krieges vgl. WANDRUSZKA, Maria Theresia 33. Das österreichische Staatsgebiet wird durch die erste Teilung Polens erweitert um folgende Gebiete: Zips [Spiš, Szepes, Spisz], Auschwitz [Oświęcim], Zator, der westliche Teil Podoliens, das später zum galizisch-lodomerischen Königreich wird vgl. BALTL, KOCHER, Rechtsgeschichte 160; zum Erwerb Galiziens, der Bukowina und des Innviertels unter Maria Theresia vgl. WAGNER, Joseph II. 618.

${ }^{56}$ Vgl. ReInALter, Joseph II. 110; BAUMgart, Joseph II. und Maria Theresia 270.
}

tisch-moralisch zu erziehen. ${ }^{57}$ Das Streben nach einem österreichischen Einheitsstaat zeigt sich in dem Versuch Josephs II., Deutsch als Amtssprache einzuführen. ${ }^{58}$ Joseph II. strebte nach einer „Verschmelzung der verschiedenen Erbländer zu einem streng zentralistischen Einheitsstaat".59 Im Rahmen der "Straffung der Verwaltung“ nimmt der Kaiser keine Rücksicht auf die Eigenständigkeit der Länder. ${ }^{60}$ Diese Reformen sorgen in einigen Gebieten der Monarchie, wie in den Niederlanden, in Ungarn, aber auch in den deutsch-böhmischen Ländern, für Aufruhr. ${ }^{61}$

\section{Eigendynamik der gemeinsamen Behörden für mehrere habsburgische Länder im institutionellen monarchisch-landständischen Dualismus}

Tezners „Landesfürstliche Verwaltungsrechtspflege in Österreich" analysiert im I. Heft (der von Hölder verlegten Ausgabe, Wien 1898) die Organisationspolitik der monarchischen Union der habsburgischen Staaten und die mit ihr verbundene Errichtung gemeinsamer Behörden für jeweils mehrere habsburgische Länder, welche, wenn auch weniger zur Zentralisierung als vielmehr zur länderspezifischen Spezialisierung den Landesbehörden übergeordnet, als Zentralbehörden die politischen Einflussmöglichkeiten der Landstände erheblich relativierten. So wurde mit der Ausgliederung der Politikberatung

\footnotetext{
${ }^{57}$ Das Theater „als moralisch-sittliche Instanz" soll "das breite Volk erziehen, lenken und leiten“ (REINALTER, Joseph II. 91); Joseph II. förderte darüber hinaus die Konkurrenz zwischen Mozart und Salieri, nach seiner Auffassung sollten trotz aller Sparsamkeit „wirkliche Verdienste“ belohnt werden (REINALTER; Joseph II. 91ff).

${ }^{58}$ LUDEWIG, Identitätskonstruktionen 93; REINALTER, Joseph II. 26.

${ }^{59}$ REINALTER, Joseph II. 25.

${ }^{60}$ Ebd. 25; BAUMGART, Joseph II. und Maria Theresia 267.

${ }^{61}$ Reinalter, Joseph II. 32.
} 
an den Geheimen Rat ${ }^{62}$ die verwaltungsrechtliche Streitbeilegung zum Kerngeschäft des „Hofrathes für die habsburgischen Länder".63 $\mathrm{Ab}$ 1620 erhält die Österreichische Hofkanzlei ${ }^{64}$ als eigene Abteilung der Reichskanzlei unter dem Österreichischen Hofkanzler die erbländischen Zuständigkeiten des Reichshofrates und verdrängt als vorbereitendes Organ für den Geheimen Rat die Reichskanzlei. Neben der obersten jurisdiktionellen Kompetenz für die Erbländer und der Zuarbeit zum Geheimen Rat verwaltete die Österreichische Hofkanzlei die von den Ständen erhobenen Steuern (Contributionale). 1654 wurde die Österreichische Hofkanzlei zu einer kollegial strukturierten Behörde unter dem Vorsitz des Hofkanzlers, der zugleich Mitglied des Geheimen Rates war. Daneben erfasst Tezners Darstellung noch die Böhmische ${ }^{65}$ und die Ungarische Hofkanzlei, ${ }^{66}$ welche jeweils formell dem obersten Kanzler des Königreichs Böhmen (durchwegs ein Mitglied des böhmischen Hochadels) bzw. dem jeweiligen Erzbischof von Gran [Esztergom] als ungarischer Großkanzler unterstanden, faktisch jedoch der (Österreichischen) Hofkanzlei.

\footnotetext{
62 TEZNER, Verwaltungsrechtspflege I, 128.

${ }^{63}$ Ebd. 122.

${ }^{64}$ Ebd. 140.

${ }^{65}$ Die Böhmische Hofkanzlei befindet sich am Wiener Judenplatz, wo heute Verfassungsgerichtshof und Verwaltungsgerichtshof ihren Sitz haben.

${ }^{66}$ Ebd. 146ff.
}

\section{Tezners Darstellung des Einflusses des Kammerwesens auf die Verwaltungsrechtspflege: Vergleichbarkeit der Kammerräte mit den Kommissaren der fran- zösischen Krone}

In Tezners Abschnitt zum Einfluss des Kammerwesens auf die Verwaltungsrechtspflege ${ }^{67}$ wird der Grundsatz der Verknüpfung von Kammerwesen und Verwaltungsrechtspflege ${ }^{68}$ deutlich: Der Hofkammer in Wien (und ihren Abteilungen mit vorrangig regionalen, daneben auch sachlichen Zuständigkeiten) oblag die Finanzverwaltung, insbesondere die indirekte Verwaltung der landesfürstlichen Kammergüter (Camerale) durch Überwachung der Länderkammern in Wien, Innsbruck, Prag [Praha] und Preßburg [Bratislava]. Für Tezner sind die Finanzbehörden die unerlässliche Stütze für „die Stärkung der monarchischen Gewalt überhaupt",69 ihre machtstrategisch unerlässliche Unabhängigkeit gegenüber Regierung und Justiz beschreiben die von Tezner zitierten Quellen als ",nomine Caesaris independenter ${ }^{\prime .70}$

\section{Kammern als Instrumente landesfürstlichen Absolutismus}

„Das Recht der freien Besetzung der landesfürstlichen Finanzstellen"71 begegnet - im Unterschied zum ständischen Ringen um die Besetzung der Zentralbehörden für Justiz und innere Verwaltung - einem nicht so großen Widerstand des Adels, „einerseits wegen der geringeren socialen Bedeutung derselben, andererseits weil sie nicht zur Ausübung hoheitlicher Gewalt, sondern nur zur Verwaltung des zur Disposition

\footnotetext{
${ }^{67}$ TEZNER, Verwaltungsrechtspflege I, 164ff.

${ }^{68}$ Ebd. 164.

${ }^{69}$ Ebd. 167.

${ }^{70}$ Zit.n. ebd. 175.

${ }^{71}$ Ebd. 165.
} 
des Landesfürsten stehenden landesfürstlichen Vermögens berufen erschienen. ${ }^{" 72}$ Damit stehen Kammerstellen hundertprozentig zur Herrscherdisposition. Zu Finanzräten kann der Monarch ihm politisch ergebene, durch ihre Ausbildung emporgekommene Bürgerliche (Roturiers) ernennen. ${ }^{73}$ Neben der Militärverwaltung ist die Finanzverwaltung Spitzenreiter in den Zentralisationsbemühungen der monarchischen Union und „unerlässliche Voraussetzung für die Stärkung der monarchischen Gewalt überhaupt ${ }^{\text {" }}{ }^{74}$ Schon nach der von Maximilian I. geschaffenen Organisation der landesfürstlichen Finanzverwaltung gibt es ein „einheitliches [Schuldenwesen] für alle drei Ländergruppen " ${ }^{75}$ Auch die Hofkammerordnung Ferdinands I. von 1537 beschwört die „rechtliche Einheit des Kammergutes in allen deutsch-österreichischen Ländern" ${ }^{76}$ Dies zeigt sich auch in der Kennzeichnung aller stationes fisci mit einem einheitlichen fiskalischen Wappen, dem zweiköpfigen Adler, sogar in Ungarn.77 „Die Schaffung eines einzigen landesfürstlichen Fiskus"78 wird erstrebt. Die Finanzbehörden treten in der österreichischen Behördenorganisation als Stütze des monarchischen Absolutismus auf. ${ }^{79}$ Daher wird die „organische Verknüpfung mit den Regierungs- und Justizbehörden" ${ }^{\prime 80}$ von letzteren als „lästig und sowohl ihrer Würde als auch dem

\footnotetext{
72 Ebd.

${ }^{73}$ Ebd. 166.

${ }^{74}$ Ebd. 167.

${ }^{75}$ Ebd. 168, Anm. 7.

${ }^{76}$ Zit.n. ebd.; in der Hofkammerordnung ist die Rede vom „kuniglich und fürstlich camerguet" (RosENTHAL, Behördenorganisation 190); sowie vom Kammergut „,in allen unsern künigreichen und landen“ (ebd. 201).

77 TeZNER, Verwaltungsrechtspflege I, 168, Anm. 7; BIDERMANN, Gesammt-Staats-Idee, I. Abt., 125, Nr. 45. 78 TEZNER, Verwaltungsrechtspflege I, 168.

${ }^{79} \mathrm{Vgl}$. Ebd.

${ }^{80}$ Ebd.
}

Zwecke ihrer behördlichen Aufgabe abträglich" ${ }^{\text {"81 empfunden. }}$

Von den Landeszentralbehörden angefangen gehören zur Verwaltung des Innern (auch Kriegsverwaltung) und zur Justiz „die Regimente, die Regierungen als Mittelstellen, der Hofrath, später die Hofkanzlei als höchste Instanz", 82 während die Finanzverwaltung durch die Kammern als Landeszentralverwaltung und durch die Hofkammer in letzter Instanz ausgeübt wird. ${ }^{83}$ "Grundsätzlich bildet die Finanzverwaltung gegenüber der von den Regierungen, dem Hofrath, der Hofkanzlei besorgten Verwaltung des Innern und der Justiz ein besonderes Ressort." ${ }^{\prime 84}$ Allerdings wird die institutionelle Unabhängigkeit zugunsten der Kammern eingeschränkt, indem Justizkollegien in Verwaltungsangelegenheiten an das Einverständnis mit den Finanzkollegien gebunden werden ${ }^{85}$ und „in Cameralprocessen Abgeordnete der Finanzkollegien mitsitzen und mitstimmen [...] müssen". ${ }^{.6}$

Die innen- und außenpolitischen Fragen jener Zeit berühren auch das landesfürstliche Finanzwesen unter zwei Gesichtspunkten. ${ }^{87}$ Zum einen ist $\mathrm{zu}$ beantworten, ob sie das „landesfürstliche Kammergut " ${ }^{\prime 8}$ betreffen. Zum anderen ist problematisch, wie „eine unmittelbare oder eine durch die Hebung der Steuerkraft der Bevölkerung vermittelte Förderung der landes-

\footnotetext{
${ }^{81}$ Ebd. 169.

82 Ebd. 170.

${ }^{83}$ Ebd. 170.

${ }^{84}$ Zit.n. ebd. 171; zum unterschiedlichen Wirkungskreis von Regiment und Rechnungskammer vgl. ADLER, Centralverwaltung unter Kaiser Maximilian I. 389.

85 TEZNER, Verwaltungsrechtspflege I, 172.

${ }^{86}$ Zit.n. ebd. 172; zur Zusammenarbeit von Regierung und Kammer durch Abhaltung gemeinsamer Sitzungen in Niederösterreich gemäß der niederösterreichischen Kammerordnung vgl. ROSENTHAL, Behördenorganisation 130, Anm. 1.

${ }^{87}$ TEZNER, Verwaltungsrechtspflege I, 173.

${ }^{88} \mathrm{Ebd}$.
} 
fürstlichen Finanzen"89 erreicht werden kann. Um diese Angelegenheiten zu klären, „müssen sich die Regierungen die mitentscheidende Mitwirkung der Kammerräthe in Regierungsund Verwaltungssachen gefallen lassen“" ${ }^{90}$

Denn während es den „Räthen der Regierung [...] entweder an jeder Bildung fehlt oder (es sich um) eine wesentlich rechtsgelehrte ${ }^{\prime \prime 1}$ handelt, sitzen die eigentlichen Verwaltungsfachkräfte und -politiker in den Kammern, weshalb die Bezeichnung mit Finanzbehörden eigentlich irreführend ist. ${ }^{92}$

„So kommt die Erledigung von Kammersachen nur den Kammern allein $z u^{\prime \prime} .^{93}$ Tezner erläutert dies anhand einiger Beispiele. Die Kammer ist gemäß der niederösterreichischen Regierungsinstruction vom Jahre 1526 ,in puris cameralibus frey“. ${ }^{94}$ Nach Beckmann ",agiret (die Grazer Hofkammer) in rebus oeconomicis Caesaris, als Eisen, Salz, Quecksilber, Maut, Zoll, Fischerey in allen J. O. Erbländern nomine Caesaris independenter; dependiret also in diesem Fall keines weges von irgend einem Tribunal“. ${ }^{95}$ Tezner kommt zu dem Schluss, dass „dies [...] die Form ist, in welcher sich damals die Erkenntniss der Nothwendigkeit der Unabhängigkeit der Verwaltung von den Gerichten und der Grenzen dieser Unabhängigkeit ausdrückt. Denn die Finanzverwaltung ist in dieser Epoche der einzige Zweig der landesfürstlichen Verwaltung, der von den auch als Justizbehörden fungirenden Regierungen deutlich und scharf geschieden ist". ${ }^{96}$ Anschließend erklärt Tezner den Be-

\footnotetext{
${ }^{89}$ Ebd. 174.

${ }^{90} \mathrm{Ebd}$.

${ }^{91}$ Ebd.

${ }^{92} \mathrm{Ebd}$.

${ }^{93}$ Ebd. 175.

94 Suttinger, Walther, Consuetudines austriacae 657; Verweis darauf in: TEZNER, Verwaltungsrechtspflege I, 175.

${ }^{95}$ BECKMANN, Idea Juris 253f. Verweis darauf in: TEZNER, Verwaltungsrechtspflege I, 175.

${ }^{96}$ Ebd.
}

griff des „pure camerale ${ }^{\prime 97}$ oder der "res oeconomi$c a^{\prime \prime}{ }^{98}$ Darunter verstehe man die "privatwirthschaftliche Verwaltung des Fiscus, es handle sich um Domänen oder um Regalien, also von rein technischen Massregeln zur Hebung seiner Ertragsfähigkeit, welche zu ihrer Durchführung nur interner Instructionen und nicht nach aussen gerichteter Rechtsnormen bedürfen, sowie von den für den Fiscus abzuschliessenden Privatrechtsverträgen ${ }^{\prime \prime}{ }^{99}$

\section{Organisationsprinzip der Verstärkung der Gerichtssenate der Regierungen durch Kammerräte}

Für die österreichische Justizgeschichte entscheidend ist das seit Maximilian I. belegte Organisationsprinzip der „Verstärkung der Gerichtssenate der Regierungen durch Kammerräte", ${ }^{100}$ welches auch die Trennung der Justiz und Verwaltung unter Josef II. überleben sollte. ${ }^{101}$ So ordnet die Schatzkammerordnung vom 13. Februar $1498^{102}$ die obligatorische Hinzuziehung von Finanzbeamten zu Rechtstagen an: , [...] und so auch dieselben unser stathalter und regennten $\mathrm{zu}$ Ynnspruck große verhor oder rechttag ansetzen [...] so sullen und mugen sy $\mathrm{zu}$ ainer jeden zeit unsern verwalter der camer [...] $\mathrm{zu}$ inen nit erfordern und nidersetzen". ${ }^{103}$ Die niederösterreichische Hofratsordnung 1523 schreibt ebenfalls obligatorisch für alle wichtigeren Prozesse Plenarsitzungen des Hofrates unter Beiziehung eines oder mehrerer Kammerräte

\footnotetext{
${ }^{97}$ Ebd.

${ }^{98}$ Ebd.

${ }^{99}$ Ebd.

${ }^{100}$ Ebd. 176.

101 Ebd. 176.

102 ADLER, Centralverwaltung unter Kaiser Maximilian I. 515ff.

${ }^{103}$ ADLER, Centralverwaltung unter Kaiser Maximilian I. 531; zit.n. TEZNER, Verwaltungsrechtspflege I, 177.
} 
zur Urteilsfindung vor. ${ }^{104}$ Unter Ferdinand I. ${ }^{105}$ sind die Abhaltung wöchentlicher sog. „Kammertage" in der Regierung belegt. ${ }^{106}$ Im 17. Jahrhundert mehren sich die belegten Instruktionen zur Anwesenheitspflicht der Kammerräte, wohl ein Hinweis darauf, dass die Regierungen versuchten, diese zu umgehen. Die niederösterreichische Regierungsinstruktion von 1625 bezeichnet die Gegenstände an den Kammertagen mit dem Ausdruck „Cammersachen und dergleichen Schirmungen". ${ }^{107}$ In der böhmischen Hofkanzleiordnung Karls VI. wird bestimmt, "dass über Justizsachen, welche fiscalische Sachen, das Aerar, dessen Jura et Praerogativa betreffen, unter Teilnahme eines oder mehrerer Hofkammerräthe beschlossen werden solle. ${ }^{\prime 108}$ Dementsprechend bejahen über die causae fiscales hinaus theresianische Prozeßakten die Mitwirkungspflicht der Kammerräte in ",allen Sachen, worunter unsers allergnädigsten LandesFürsten interesse, Hoheit oder die allgemeine

\footnotetext{
104 RosentHAL, Behördenorganisation 220: „und so aber ain grosse und tapfere urtl vor augen ist, so soll der ganz Hofrat uber dieselben acta sizen unde wo von nöten sein will, ainen oder mer rät aus unser raitcamer darzue erfordern und dieselben urtl mit besameltem rat mit ainander besliessen." Verweis darauf bei TEZNER, Verwaltungsrechtspflege I, 177 Anm. 30.

${ }^{105}$ Ferdinand I. (1503-1564) steht lange im Schatten Karls V., den er als Statthalter vertritt (SIMÁNYI, Ferdinand von Habsburg 70). 1558-1564 ist er Kaiser des Heiligen Römischen Reichs deutscher Nation (NIEDERSTÄTTER, Herrschaft Österreich 102). Wie bereits erwähnt führt er die unter Maximilian I. begonnene Reform der Behördenorganisation weiter (Ebd. 103; SCHIEDER, ENGEL, Handbuch 548). In Zeiten der Reformation ist Ferdinand I. um Ausgleich bemüht (SIMÁNYI, Ferdinand von Habsburg 291; NIEDERSTÄTTER, Herrschaft Österreich 106).

106 So in den Jahren 1527 und 1539 vgl. TeZNER, Verwaltungsrechtspflege I, 177.

${ }^{107}$ Die Instruction von Kayser Ferd. II. vom 4. Martii An. 1625, Zit. in: SutTINGER, WALTHER, Consuetudines austriacae 656; Verweis darauf in: TEZNER, Verwaltungsrechtspflege I, 177, Anm. 33.

108 Zit.n. ebd. 183.
}

Wolfahrt versiret.“109 Die Gleichsetzung von landesfürstlichem und öffentlichem Interesse entspricht dem aufgeklärten Absolutismus zur Zeit Maria Theresias, und von Tezner zitierte Entscheidungen der obersten Justizstelle belegen eine durchaus recht großzügige Ausdehnung auf privatrechtliche Fragen von Untertänigkeitsprozessen. ${ }^{110}$ In der Sprache Beckmanns liest sich die Anwesenheit der Kammerräte zur Sicherung des Herrscherinteresses folgendermaßen: „Wann [...] cameral-Sachen, ad contradictorium kommen, so werden diese streitige cameral-Händel medicante Procuratore camerae, vor der hochlöblichen Regierung in pleno, concurrentibus regulariter tribus Dominis Camerae consiliariis, solenniter proponiret, disputiret, examiniret und decidiret $^{\prime \prime}{ }^{111}$

Die Anwesenheit von Kammerräten in Regierungen/Justiz ist mit Kommissaren in der französischen Justizgeschichte ${ }^{112}$ vergleichbar: "Als Mandatare der sie delegierenden Finanzcolle-

\footnotetext{
109 Zit.n. BECKMANN, Idea Juris 399f; Verweis darauf in: TEZNER, Verwaltungsrechtspflege I, 178.

${ }^{110}$ Ebd.; „Eine Entscheidung der obersten Justizstelle vom 31. October 1765 betrifft den Streit einer Herrschaft mit unterthänigen Gemeinden um den Inhalt des der ersteren an den unterthänigen Gründen zustehenden Weiderechts. Bei der Regierung sowohl als auch bei der Justizstelle nehmen an der Urtheilsschöpfung Kammerräthe theil. Die ganze Judicatur über diesen Gegenstand ist von hohem Interesse, insoferne sie uns den Kampf zwischen den Vertretern des positiven Rechts und der formalen Jurisprudenz mit den agrar-politischen Tendenzen der damaligenZeit im Innern des höchsten Gerichtshofes vorführt, wobei sich übrigens auch ein Theil der Juristen allerdings auf Kosten der Jurisprudenz und mittels einer dem römischen Rechte hohnsprechenden, rabulistischen Verdrehung seiner Begriffe auf die Seite der Unterthänigen schlägt." So zitiert in: TEZNER, Verwaltungsrechtspflege I, 178, Anm. 37.

${ }^{111}$ BECKMANN, Idea Juris 254; zit. in: TEZNER, Verwaltungsrechtspflege I, 179.

112 Vgl. auch die Hinweise ebd. 180 auf das Vorgehen des Pariser Parlement gegen "commissaires departis" und "intendants".
} 
gien"113 sind sie die gegen die Selbstständigkeit des ständisch gesinnten Richtertums gerichtete "Sperrvorrichtung zur Sicherung der landesfürstlichen Interessen". ${ }^{114}$ Dies wird eklatant in den Vorgaben, die mitwirkenden Kammerräte als eigenständige Kurie der Regierungs- und Justizräte gegenüberzustellen ${ }^{115}$ mit der Konsequenz, dass bei Uneinigkeit mit der Entscheidung der Regierungs- und Justizräte bereits das Votum nur eines einzigen die Kammer repräsentierenden Kammerrates genügt, um mit „Stimmengleichheit" (vota paria) ein votum ad imperatorem, also die Devolution der Entscheidung an den Landesfürsten herbeizuführen.

Andererseits hat die Verklammerung der Regierungen/Justiz mit der Finanzverwaltung niemals die formale Institutionengrenze dahingehend verwischt, dass die Finanzkammern als Gerichte alleinige Justizgewalt ausüben könnten,116 also als Appellationsinstanz ${ }^{117}$ isolierte Justizgewalt ausüben. Um mit der niederösterreichischen Hofkammerordnung Ferdinands I. zu sprechen, haben die Hofkammerräte „keine macht und gewalt in dem, was justicia betrifft, zu handeln, sie kann nur sine strepitu judicii, extra causas in judicio contravertendas", ihre Erledigungen sind keine Judikate (,judicii“). ${ }^{118}$ Deshalb werden die

\footnotetext{
113 Ebd. 181.

114 Ebd. 183.

${ }^{115}$ Die Regierungsinstruktion Kaiser Ferdinand II. vom 4. 3. 1625 fordert: „Cammer-Sachen und dergleichen Schirmungen seynd vor Regierung abzuhandeln in Beyseyn der Cammer-Räth“, zit.n. SUTTINGER, WALTHER, Consuetudines austriacae 656; Verweis darauf in: TEZNER, Verwaltungsrechtspflege I, 177; zur Organisation durch Zusammenarbeit von Justizkollegien und Kammerbeamten vgl. TEZNER, Verwaltungsrechtspflege II, 116.

116 TEZNER, Verwaltungsrechtspflege I, 184.

117 Ebd. 185.

118 Zit.n. ebd. 188; aus der Tiroler Kammerordnung von 1536 wird deutlich, dass die Kammerräte in Sachen der "justitia" nur beratende Funktion ausüben (ROSENTHAL, Behördenorganisation 259f).
}

Finanzbehörden auch „officia extranea, accessoria"119 genannt.

Dieses vom Misstrauen gegen die feudalen Richter getragene Organisationsprinzip, den Regierungen als landesfürstliche Justizkollegien zur Wahrung der landesfürstlichen Interessen Kammerbeamte beizugesellen, macht auch vor der 1749 geschaffenen Justizstelle nicht halt: Das von einem einzigen Kammerrat vertretene Kammervotum steht stimmengleich einem einmütigen Justizvotum gegenüber und kann durch die Devolution an den Landesfürsten den Fall dadurch der Justizstelle entziehen. Der Vortrag des Vizepräsidenten der Justizstelle Graf Sinzendorf vom 25. September 1776 stellt klar, ${ }^{120}$ dass die durch die Devolution an den Landesfürsten gängige Kabinettsjustiz auf dem Gebiet des landesfürstlichen Interesses besonders peinlich oder misslich sei: „[...] und Euere Maitt. könnten Sich andurch entübrigen, bei den Rechtshändeln dero Eigenen aerarii Selbst unmittelbar die entscheidende Erkanntnus zu schöpfen. [...] Euer Majestät soll man dahero unterwerfen, ob Höchstdieselbe die Stimmen deren in revisorio beisitzenden cameral-und Bancalrepräsentanten ebenfalls nur pro voto virili gelten zu lassen, und also die secundum majora ausfallenden conclusa künftig ohne weiteren in vim sententiae expediren zu lassen geruhen". ${ }^{121}$ Die Kaiserin antwortet, „dass es in Revisorio bei dem bestehenden Zustande zu verbleiben habe: Dieß ist schon abgethann als eine Sache, die das aerarium allein angehet, worüber ganz leicht eine schon hergebrachte Vorsicht Vor das Cammerale abgeschafet, auch erwartend, dass die Stellen selbes künftig besser Besorgen, damit nicht wiederumb eine andere Vorkehrung außgemacht

\footnotetext{
${ }^{119}$ BIDERMANN Gesammt-Staats-Idee, I, 125, Nr. 45, Abs. 3; zit. in: TEZNER, Verwaltungsrechtspflege I, 189, Anm. 60.

${ }^{120}$ Zit.n. TEZNER, Verwaltungsrechtspflege II, $120 \mathrm{ff}$.

${ }^{121}$ Zit.n. ebd. 121.
} 
werden“.122 Daraus schlussfolgert Tezner, "dass die bestehende Organisation der Verwaltungsrechtspflege eine unerlässliche Forderung der Politik sei, und dass die Justizstelle auf die wiederholte Zurückweisung ihres Reformvorschlages verwiesen wird“. ${ }^{123}$

Eine „Allerunterthänigste Nota die bey der Obristen Justizstelle höchst wichtigen Gebrechen der reinen Justiz Fliege betreffend" vom 27. Dezember $1779^{124}$ stellt einige über diesen zurückgewiesenen Vorschlag hinausgehende Forderungen auf. Dem Repräsentanten soll „überhaupt nur ein informatives, kein decisives Votum eingeräumt werden“. ${ }^{25}$ Zudem werden "alle Eingriffe in die Justiz durch kaiserlichen Machtspruch“126 kritisiert: „Jeder Machtspruch ist äusserst bedenklich, da bey Ertheylung des Rechtes, welches immerhin mir von der genauen ordnungsmässigen Verhandlung und genauen Durchforschung abhängt, die höchste Macht nie vordringen kann, ohne sich der nächsten Gefahr des Unrechts auszusetzen; dahingegen der Rechtsspruch selbst seine sicherste Bedeckung erhält, wenn selber die Ordnung und den Vorgang derjenigen, die solche mit vorsichtiger Auswahl bestellet hat, nicht hemmt. Eure Majestät dürften sich daher bewogen finden, keinem auf den Ausspruch aus höchster Machtvollkommenheit gerichteten Ansuchen statt zu geben“. ${ }^{127}$

\footnotetext{
122 Zit.n. ebd. 123.

${ }^{123}$ Ebd. 124.

124 Zit.n. ebd.

${ }^{125}$ Zit.n. ebd. 124, Anm. 89a; nach LÖNING, Gerichte und Verwaltungsbehörden 442 folgt Minister v. Schrötter „dem von Svarez aufgestellten Grundsatze [...], daß der Justiz alles Dasjenige, was Privatrecht und andere Verbindlichkeiten ohne Unterschied der Objekte und Subjekte betrifft, ausschließend überlassen und die Kammer-Justiz beseitigt werde.“

${ }^{126}$ Zit.n. TEZNER, Verwaltungsrechtspflege II, 124; zur Problematik des Machtspruches vgl. LEHNE, Geschichte der Verwaltungsstreitsache 29.

127 Zit.n. TEZNER, Verwaltungsrechtspflege II, 124.
}

Die Kaiserin lehnt eine derartige Einschränkung ihrer Macht ab: „Ich weiss mich gar nicht zu erinnern, dass einen Machtspruch gethan und hätte die oberste Justiz-Stelle Mir alle diejenigen vorzulegen, die sie also davor haltet. Ich will weder mir noch Meinem Nachfolger die Hände binden, das, wenn es nötig findete, selben $\mathrm{zu}$ verhängen ins künftige, indem es niemals ohne reifer Ueberlegung geschehen wird, und wir allein Gott Rechenschafft zu geben haben unserer Handlungen“. ${ }^{128}$

Die oberste Justizstelle selbst ist "gegen Machtsprüche nicht eingenommen, wenn sie der Sicherung des Rechtsweges gegen verwaltungsbehördliche Erkenntnisse oder der Beseitigung von Zweifeln über das Offenstehen derselben gewidmet sind". ${ }^{129}$ In einer Fußnote beschreibt Tezner einige Fälle, in denen die Kaiserin ",auf die schon erhaltene Vorbescheidung “130 verweist, ohne „auf den Rechtsweg bei der Justizbandcodeputation $\mathrm{zu}$ verweisen “.131 In diesem

\footnotetext{
${ }^{128}$ Zit.n. ebd.

129 Ebd. 125.

${ }^{130}$ Ebd. 125, Anm. 90.
}

${ }^{131}$ Ebd. 125. Dort beschreibt Tezner die genannten Fälle folgendermaßen: „Einmal legt die Justizstelle die mit kaiserlicher Entschliessung erfolgte Verweisung einer Beschwerde gegen ein Hofkammerdecret vor die Justizbancodeputation als eine wirksame Begründung der sachlichen Competenz dieser Behörde zur Entscheidung über den erhobenen Anspruch aus. Diese Competenz könne der Monarch tanguam fons durch Verfügung für den Einzelfall festsetzen. Ein anderesmal schreitet jemand gegenüber einem Hofkammerdecret, mit welchem ihm im Verwaltungswege ein Theil einer Entschädigungsforderung aberkannt, worden ist bei der Kaiserin um einen Machtspruch ein, oder um Zulassung der Entscheidung über seinen Anspruch durch die Justizstelle. Entgegen dem Antrage der Justizstelle vom 9. October 1776, den Gesuchsteller auf den Rechts weg bei der Justizbancodeputation zu verweisen, entscheidet die Kaiserin, der Supplicant ist mit diesem seinem Gesuch ein- für allemal auf die schon erhaltene Vorbescheidung zu verweisen. Diese Resolution wird vor ihrer Ausfertigung der obersten Justizstelle aber nur zu dem Zwecke mitgetheilt, dass 
Zusammenhang beschließt die Kaiserin wiederum: „Da diese Sache von Behörden als schon solchen gestalt erörtert und erhoben worden, dass solche gar nicht mehr ad viam juris qualificirt ist [!], so hat es bei meiner letzten Resolution sein gänzliches Verbleiben. ${ }^{\text {132 }}$

Die Nota der obersten Justizstelle kritisiert zudem „die Endlosigkeit des Rechtsmittelzuges und die Rechtsunsicherheit, welche durch kaiserliche Gewährung von Superrevisionen hervorgerufen werde. "133

„Diese Bewilligung führet [...] nothwendig einen Eingrief in die gesätze und Verfassung in das erworbene Recht des gegentheils und eine betriebte Ungewissheit für jedes Eigenthum an sich. Anhänger und auch Gründe für die entgegengesetzte meinung beweisen noch keine Ungerechtigkeit diese aber nur allein, wenn sie aufgeleget wäre, könnte den letzten Spruch entkräftigen."134 Die Kaiserin reagiert auf das Ansuchen, "keine Superrevision, wenigstens nicht ohne Einrathen der Justizstelle zu bewilligen"135

sie von dem Inhalte Kenntnis" nehme. Nichtsdestoweniger drängt dieselbe mittels der allerunterthänigsten Vorstellung vom 13. 11. 1776 sich der Kaiserin als Gutachter auf und beantragt in derselben, dem Bescheide die Fassung zu geben: „Der Bittsteller wird von hier (d. i. von der letzten Instanz) abgewiesen(also wegen Ausserachtlassung der Ordnung des Instanzenzuges) und den Hinweis auf das Hofkammerdecret zu streichen. Sonst könnte der Supplicant der Meinung sein (als ob bei der klaren Fassung der Resolution der geringste Zweifel an der Richtigkeit dieser Meinung hätte entstehen können!), es sei ihm auch der Rechtsweg in prima instantia abgeschnitten. Schliesslich wird die Gerechtigkeitsliebe der Kaiserin beschworen, welche am allerwenigsten bei Forderungen gegen das Aerarium hintangesetzt werden dürfe." 132 Zit.n. TEZNER, Verwaltungsrechtspflege II, 125. ${ }^{133}$ Ebd.

${ }^{134}$ Zit.n. ebd. 125f; ebd. 126, Anm. 91 verweist in diesem Zusammenhang auf „die moderne Controverse über die Bedeutung und die Grenzen der materiellen Rechtskraft auf dem Gebiete des Verwaltungsrechts [...], (sowie darauf) [...], dass selbst die Justizstelle nicht für ihre absolute Geltung eintritt.“

135 Zit.n. TEZNER, Verwaltungsrechtspflege II, 126. folgendermaßen: „Da hin einverstanden, dass zum besten, die oberste Justiz Stelle zu vernehmen wäre, ohne mich dessenthalben mehrens zu Verbinden, als jetzo geschehen. “136

Die Kontrolle „der Anträge der Justizstelle durch den Staatsrath [wird] als mit der Bedeutung eines obersten Gerichtes unvereinbar"137 angesehen: „Nicht mit der Benennung noch weniger mit der Verfassung einer obersten Justizstelle, der doch die letzte Besorgung der Gerechtigkeit im Staate überantwortet ist, ist es Vereinbahrlich, dass auch diese denen Entscheidungen des Staatsrathes gleichsam untergeordnet seyn solle, da es für den guten zuverlässigen Gang der geschäften selbst eine unmöglichkeit ist, sich zu Versprechen, dass dort genauer geprüft, reyfer überlegt und gründlicher geurtheilt werde, als es von besagter Christen Justiz Stelle geschiehet. Gegen Eure Majestät wird die Justizstelle über jede wider sie vorkommende Beschwerde sich pflichtmässig auszuweisen hinfortan in Bereitschaft stehen." 138

Tezner deutet die Reaktion der Kaiserin auf den letzten Antrag anhand einer Randbemerkung derselben $^{139}$ folgendermaßen: „Das Votum der Justizstelle sei in jenen Fällen, wo kaiserliche Entscheidung gefordert sei, Gutachten und nicht richterliches Erkenntniss. Darum sei auch das Superarbitrium des Staatsrathes keine Ueberprüfung eines richterlichen Erkenntnisses. Allein auch das Superarbitrium des Staatsrathes sei kein richterliches Urtheil, denn der Staatsrath sei keine Stelle, d. i. nicht an der Vollziehung betheiligt. Die Justizstelle habe deshalb die an

\footnotetext{
${ }^{136}$ Zit.n. ebd.

137 Zit.n. ebd.

138 Zit.n. ebd.

139 Zit.n. ebd.: „Der Staatsrath ist keine Stelle, was unter der (nun folgt ein unleserliches Wort, vielleicht original?) unterschrift kommt, machet den ausschlag. Wan wir Von der obristen justizstelle Vorträge auch in processsachen fordern, so ist selber einrathen noch kein spruch. Selber wird erst durch die resolution formirt."
} 
sie mit der Originalunterschrift der Kaiserin herablangenden Entschliessungen als Entscheidungen der Kaiserin und nicht als solche des Staatsrathes zu behandeln. ${ }^{\prime 140}$

Tezner wertet dies als die Erhaltung einer „staatsrechtliche[n] Einrichtung, vermöge welcher das höchste landesfürstliche Gericht wahrhaftes Gericht nur soweit ist, als ihm eigene Entscheidung delegirt ist, wogegen ihm aber nur die Stellung einer begutachtenden Behörde zukommt, wo wegen Stimmengleichheit oder Stimmenzersplitterung die Entscheidung des Landesfürsten einzutreten hat, nachweislich bis gegen das Ende des 18. Jahrhunderts und allem Anscheine nach bis zum Ausgang der absolutistischen Epoche. Damit hängt es auch zusammen, dass bei allen Acten der persönlichen Gerichtsbarkeit des Landesfürsten die oberstgerichtlichen vota ad imperatorem dem Obergutachten des jeweiligen Kronrathes unterliegen. Wie ehemals der Hofrath und die Hofkanzleien die Ueberprüfung ihrer vota durch den Geheimrath über sich ergehen lassen mussten, so unterliegen nunmehr die oberste Gerichtsstelle und die böhmisch-österreichische Hofkanzlei dem Superarbitrium des Staatsrathes. Diese Art der persönlichen Ausübung der Gerichtsgewalt will Maria Theresia auch für die Zukunft festhalten. “141

Vom 11. Jänner 1780 ist ein Handschreiben der Kaiserin an den Präsidenten der Obersten Justizstelle Graf Seilern überliefert, in welchem das votum curiatum abgeschafft wird. ${ }^{142}$

\footnotetext{
${ }^{140}$ TEZNER, Verwaltungsrechtspflege II, 126f.

${ }^{141}$ Ebd. 127.

142 Zit.n. ebd. 127 f.
}

\section{Wider das "rechtsstaatliche“ Missverständnis absolutistischer Verwaltungs- und Justizreformen}

\section{Territorialgewinn der kaiserlichen Behörden zu Lasten der Stände}

Der Terraingewinn der kaiserlichen Zentralbehörden gegenüber den ständischen Behörden in den verschiedenen Ländern lag zum einen an der zunehmenden Differenzierung der Gebiete der Staatstätigkeit und zum anderen an der auBenpolitischen Herausforderung durch die türkische Bedrohung. Neue politische Aufgaben im zwischenstaatlichen Raum, im Bereich des Wehr-, Kirchen- und Polizeiwesens konnten nur vom (kaiserlichen) Landesherrn geregelt werden, ständische Rechte waren demgegenüber durch das Herkommen fixiert. Der militärische Erfolg über die Türken 1683 und der sich anschließende Siegeszug in Ungarn ${ }^{143}$ unter Prinz Eugen (1703-1736 Hofkriegsratspräsident) ${ }^{144}$ bis tief in den Balkan hinein führt zum österreichisch-ungarischen Vielvölkerstaat, welcher zwar mit seinen „Erblanden“ zum Reich gehörte, im Übrigen aber die politische Vormacht und Schutzherrschaft für zahlreiche ost- und südosteuropäische Völker und Volksgruppen bildete. Dadurch wurden Organisationsstrukturen notwendig, welche auf die Zentrale ausgerichtet waren: Die "Militärgrenze" bildete bereits Ende des 16. Jahrhunderts einen aus „Wehrbauern bestehenden neuen Verwaltungsdistrikt, der sich von der nördlichen Adria [...] bis zur Drau nach Ungarn erstreckte“.145 „Dieser Distrikt ge-

\footnotetext{
${ }^{143}$ Kaiser Leopold I. (1658-1705) gewann Ungarn zurück und erwarb Siebenbürgen im Frieden von Karlowitz vgl. SCHIEDER, WAGNER, Handbuch 429. ${ }^{144}$ Unter Joseph I. (1705-1711) und Karl VI. (17111740); vgl. KотULLA, Verfassungsgeschichte 248, Rz. 975.

${ }^{145}$ Ebd. 250, Rz. 989.
} 
noss weitgehende Selbstverwaltungsrechte und unterstand unmittelbar dem kaiserlichen Landesherrn“. ${ }^{146}$ Allerdings wird das Heer erst während des Dreißigjährigen Krieges der landesherrlichen Gewalt effektiv zentral unterstellt. ${ }^{147}$

Prinz Eugen gelang es sogar vorübergehend, sich die lokalen Heeresversorgungsstellen unterzuordnen, ${ }^{148}$ auch wenn eine dem preußischen Kommissariatswesen ${ }^{149}$ vergleichbare Einrichtung niemals denkbar war: ohne die Mitwirkung der Stände ließ sich die kaiserliche Armee vorerst nicht ausheben oder versorgen.

Unter Maria Theresia kam es zu einer gründlichen Reform des Behördenwesens. 1742 entwickelt sich die Geheime Haus-, Hof- und Staatskanzlei aus einer Abteilung der Hofkanzlei als „Vorläufer des späteren Ministeriums des Äußeren".150 Im Rahmen der Zentralisierungsbestrebungen wurden die österreichische und die böhmische Hofkanzlei abgeschafft und ihre Kompetenzen auf zwei zentrale Behörden übertragen, das Directorium in publicis et cameralibus, sowie die Oberste Justizstelle. ${ }^{151}$ Das Direktorium war sachlich zuständig für „die gesamte politische (=innere) Verwaltung und die Finanzverwaltung“, die Justizstelle für „die Justizverwaltung und die Rechtsprechung in höchster Instanz". ${ }^{152}$ Formell unterstand es der Conferenz in Internis, einem beratenden Gremium, das allerdings über keine exekutive Macht

\footnotetext{
146 Ebd.

147 Ebd. 251, Rz. 990.

${ }^{148}$ HerRe, Prinz Eugen 27ff.

${ }^{149} \mathrm{Zu}$ diesem Gegensatz zwischen Österreich und Preußen vgl. PrOMITZER, Merkwürdige Flucht 293.

150 OGRIS, Staats- und Rechtsreformen 59.

${ }^{151}$ Ebd.

152 Ebd.; darüber hinaus ist das Direktorium zuständig für „die Finanz-, Handels- und Gewerbsangelegenheiten“ MAASBURG, Oberste Justizstelle 7, Anm. 10.
}

verfügte und nur Angelegenheiten behandelt, die bereits das Direktorium untersucht hat. ${ }^{153}$

1760 wird - im Sinne der Zentralisierungsbestrebungen - unter dem Einfluss von Kaunitz eine „oberste beratende und antragstellende Behörde",154 der Staatsrat, gegründet.155 1761 wird das Directorium in publicis et cameralibus aufgelöst und durch die böhmische und österreichische Hofkanzlei ersetzt, wobei die Finanzverwaltung nicht mehr zu ihren Kompetenzen zählt. ${ }^{156} 1782$ entstand unter Joseph II. die Vereinigte Hofstelle durch Zusammenlegung der Hofkammer und der böhmischen und österreichischen Hofkanzlei. ${ }^{157}$ Die ungarische, siebenbürgische und illyrische Hofkanzlei wurden vereinigt. ${ }^{158}$ Das Finanzwesen wird in der Ära Kaunitz aus organisatorischen Gründen von der politischen Verwaltung getrennt, das Justizwesen hingegen einbezogen. ${ }^{159}$ Die Verwaltungsreformen unter Maria Theresia und Joseph II. könnten als Mittel zur Sicherung der Macht des Staates $^{160}$ angesehen werden, die trotz einiger Neuerungen nach 1760, weitgehend bis 1848 in Geltung bleiben. In der Sekundärliteratur wird vertreten, dass die Kaunitzschen Reformen der 1760er Jahre Modifikationen des Haugwitzschen Systems sind. ${ }^{161}$ Anlass für die Änderungen

${ }^{153}$ ADAM, Political Economy 30, Anm. 20; zur Tätigkeit des Direktoriums vgl. MEgERLE, Ursprüngliche Errichtung 5.

154 POHL, VocelKA, Habsburger 302.

${ }^{155}$ Ebd. 302; Dieser ist mit „drei Mitgliedern des Herrenstandes und drei Mitgliedern des Gelehrten- und Ritterstandes" besetzt; MATSCH, Auswärtiger Dienst 68.

${ }^{156}$ OGRIS, Staats- und Rechtsreformen 60; POHL, VOCELKA, Habsburger 302.

${ }^{157}$ LEVY, Habsburg Policy and Italian Tyrol.

158 BALTL, KOCHER, Rechtsgeschichte 171.

${ }^{159}$ HOKE, Rechtsgeschichte 235f.

160 OGRIS, Staats- und Rechtsreformen 60.

${ }^{161}$ SHEEHAN, German History 48; OGRIS, Staats- und Rechtsreformen 61, spricht sogar davon, "daß das Haugwitzsche System den Sturz (1760) und den Tod (1765) seines Schöpfers, über alle späteren Veränderungen und Verwässerungen hinweg, überlebt hat"; 
durch Kaunitz war die Tatsache, dass das Direktorium aufgrund seiner weitreichenden Kompetenzen ineffizient wird. ${ }^{162}$

Die Stärkung der kaiserlichen Behörden zu Lasten der Stände geht vor allem auch auf den Einfluss des Kammerwesens auf die Verwaltungsrechtspflege zurück. Diese schon unter Ferdinand I. begründete Struktur bleibt prägend, so dass die Argumentation Tezners von der Kontinuität der Verwaltungsrechtsprechung gegenüber der einleitend dargestellten Kritik Freiherr von Lemayers zu bevorzugen ist. Dies lässt sich auch in den größeren Zusammenhang der Rechtspflege als Verwaltungsaufgabe der landesherrlichen Justizverwaltung stellen.

\section{Rechtspflege als Verwaltungs- aufgabe der landesherrlichen Justizverwaltung}

Die „Handhabung der Gerechtigkeit in Privatangelegenheiten und Partheysachen "163 oblag den landesherrlichen Justizkollegien als Verwaltungsaufgabe. Die Einordnung der ordentlichen Rechtspflege als allgemeine Verwaltungsaufgabe demonstriert die Janusköpfigkeit der landesherrlichen Justizkollegien als oberste Verwaltungsstellen und oberste Gerichtsbehörden, welche aus territorialstaatlicher Sicht für die Effektivität und das Machtpotential der Territorialgewalt grundlegend war. ${ }^{164}$ Sie hatten die Justiz gemäß den Regierungszielen auf den Landesfürsten zu zentralisieren und Vollzugsdefizite der ständischen Justizverwaltung abzubauen. ${ }^{165}$

a.A. BAHLCKE, Ungarn und die Reichskirche 228, wonach das "System Haugwitz durch das System Kaunitz ersetzt wurde".

162 OGRIS, Staats- und Rechtsreformen 60.

163 FLÖRCKE, Policey-Sachen $\S 3$.

${ }^{164}$ MAIER, Staats- und Verwaltungslehre 185ff.

${ }^{165} \S 22$ Reglement, was für Justiz-Sachen denen Krieges- und Domainen-Cammern verbleiben, und welche vor die Justiz-Collegia oder Regierungen gehören,
Den Machtzuwachs der landesherrlichen Justizkollegien und Kammern zu Lasten der ständischen Justizverwaltung analysiert Veit Ludwig von Seckendorff treffend in seiner Schrift „Teutscher Fürsten-Staat" (1656) dahingehend, dass „landesherrliche Gerichte vieles an sich gezogen hätten [...] den Hofgerichten nur wenig autorität mehr übrig geblieben [sei]“. ${ }^{166}$ Solange der Aufbau territorialstaatlicher Verwaltungsorganisation auf die Mitwirkung der lokalständischen Herrschaftsträger angewiesen war, wurden letztere mit der Vergabe von Privilegien gewonnen. ${ }^{167}$ In den vom Territorialherrn verteilten Privilegien lag keine Förderung, sondern eine Schwächung der ständischen Rechte. Denn eine vom Landesherrn verliehene privilegierte Sonderstellung schloss die Ungleichheit kraft eigenen Rechts gegenüber der als einheitlich gedachten Territorialherrschaft und damit originäre ständische Justizrechte aus. Nur derivative ständische Justizrechte duldete das landesherrliche summum imperium. ${ }^{168}$ Ständische Justizrechte wurden zu Privilegien, ${ }^{169}$ zu „Freyheitsbegnadi-

de dato Potsdam, den 19. 6. 1749: „Wann derer Beamten Justitiarii und Magisträte wegen übler Administration der Justiz verklaget werden; so stehet denen Justiz-Collegiis frey und lieget ihnen ob, nach Beschaffenheit der zu ihrem Ressort gehörigen Sache Acta $\mathrm{zu}$ avociren, und die nöthige Verordnungen ergehen zu lassen, sie auch, wenn die Beschuldigung und Klage gegründet gefunden wird, in Justiz-Sachen $\mathrm{zu}$ cassiren, $\mathrm{zu}$ suspendiren oder zu bestraffen, und die Strafe zur Execution zu bringen." (zit. in Corpus Constitutionum Marchicarum, No. LXVI, 169).

166 SECKENDORFF, Teutscher Fürsten-Staat II, 9, 243.

${ }^{167}$ KLIPPEL, Politische Freiheit und Freiheitsrechte 96ff., 108; DERS., Privileg im deutschen Naturrecht $335 f$.

${ }^{168}$ BOEHMER, Introductio in ius publicum, 584f., 611, Anm. d.

169 PUfENDORF, De jure naturae et gentium, lib.3, cap. 2, §9. Vgl. zu Samuel Pufendorf BeHME, Samuel von Pufendorf 27ff.; DENZER, Moralphilosophie und Naturrecht 55ff.; DÖHRING, Geschichte der deutschen Rechtspflege 8ff.; FIORILLO, Pufendorf 15ff.; GEYER, Pufendorf 25ff.; GOYARD-FABRE, Pufendorf 10ff.; LAURENT, Pufendorf 26ff.; MÜLLER, Menschenrechte bei 
gungen" laut Wolff, ${ }^{170}$ die aufgehoben werden konnten. ${ }^{171}$ Durch die Degradierung zu Privilegien wurden ständische Rechte vom Willen des Herrschers abhängig. Insoweit gab sie das ältere Naturrecht der absolutistischen Staatstheorie preis. ${ }^{172}$

\section{Gegenargumente gegen eine konstitutionelle Bindung der Justizhoheit des aufgeklärten Monarchen}

Die Theresianische Justiz- und Verwaltungsreform mündet in die Errichtung des Directorium in Publicis et Cameralibus als oberster Verwaltungsstelle, in welcher auch österreichische und böhmische Hofkanzlei aufgehen, sowie in der Schaffung der Obersten Justizstelle als Oberster Gerichtshof in den Erblanden, ${ }^{173}$ an deren Stelle am 7. August 1850 der Oberste Gerichtshof ${ }^{174}$ tritt. Im Gegensatz zur Justizstelle ist dieser nur Gericht, die administrativen Aufgaben übernimmt 1848 das Justizministerium. ${ }^{175}$ Die Entwicklung unter Maria Theresia wird deutlich in einem Auszug aus dem politischen Testament der Kaiserin 1750/1751: „,...] habe alle Cameralia der ehemaligen Hofkammer in denen öster-

Samuel Pufendorf 15ff.; Palladini, Hartung, Pufendorf 11ff.; SAASTAMOINEN, Pufendorf 34ff.; Welzel, Naturrechtslehre 9ff.

${ }^{170}$ WoLfF, Grundsätze § 1047. Vgl. zu Christian Wolff: BACHMANN, Naturrechtliche Staatslehre 11ff.; FRAUENDIENST, Wolff als Staatsdenker 9ff.; GIERKE, Johannes Althusius 19ff.; HellmUTH, Naturrechtsphilosophie 17ff.; HOFFMANN, Staatsphilosophischen Anschauungen 32f.; LUIG, Pflichtenlehre 209ff.; SCHNEIDERS, Christian Wolff 38ff.; STIPPERGER, Freiheit und Institution 17f.; STUPP, Mos geometricus 10f.; WUNNER, Christian Wolff 11ff.

171 WOLFF, Grundsätze $\S 1047$; DERS., Jus naturae, Part $8, \S 873$.

${ }^{172}$ Gliederungspunkt IV. 2. bereits in Teilen erschienen in: MÜßIG, Recht und Justizhoheit 220ff.

${ }^{173}$ Vgl. TEZNER, Verwaltungsrechtspflege II, 84ff.

${ }^{174}$ Kaiserliches Patent vom 7. 8. 1850, § 1 (RGBl. 325).

175 WALTER, Zentralverwaltung 279. reichisch- und böhmischen Ländern völlig abgenommen und deren Activität nur auf die Hungarica [...] eingeschränkt, die beiden Kanzleien aber gar aufgehoben, mithin alle Publica und Cameralia $[. .$.$] dem neu bestellten Directo-$ rio übergehen. Demnächst zur Besorgung der heilsamen Justiz vor sämmtliche böhmisch- und österreichische Erblande eine Obristjustizstelle bestellt $[\ldots] .{ }^{\prime \prime} 176$

Während die Auflösung des Directoriums in Publicis et Cameralibus 1760, die Neuschaffung der Vereinigten Böhmisch-Österreichischen Hofkanzlei, ihre Zusammenlegung unter Joseph II. mit der Hofkammer zur „Vereinigten Hofstelle" einer weiteren Bearbeitung vorbehalten bleiben, konzentrieren sich die Ausführungen auf der Grundlage meiner Vorarbeiten in "Recht und Justizhoheit" auf das rechtsstaatliche Missverständnis ${ }^{177}$ der „Errichtung einer organisatorisch von der höchsten Centralverwaltungsstelle vollständig abgetrennten Justizverwaltungs- und Gerichtsbehörde" ${ }^{\text {" }}{ }^{178}$

Selbst wenn das Folgejahr 1749 nach Erscheinen des Montesquieuschen Esprit des Lois $1748 \mathrm{zu}$ Fehlschlüssen verleitet, geht es um grundlegende Aussagen zur Stellung des Richters im Absolutismus, zur Justizgewalt in der politischen Theorie des aufgeklärten Absolutismus und zur landesherrlichen Machtvollkommenheit statt konstitutioneller Beschränkung der Justizhoheit. Es wird deutlich, wie Recht Tezner hatte, davor zu warnen, die Zuweisung aller Streitsachen an die Justiz, sie mögen sich „auf das publicum et

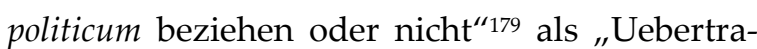
gung der 1748 aufgestellten Montesquieuschen Lehre von der Theilung der Gewalten ${ }^{\prime 180}$ misszuverstehen.

\footnotetext{
176 HOKE, ReITER, Quellensammlung 277, Rz. 1330.

177 TEZNER, Verwaltungsrechtspflege II, 89.

${ }^{178}$ Ebd. 86

${ }^{179}$ Ebd. 89

180 Ebd.
} 
a. Die Beschränkung der Justizsache als Streitigkeit um das "Mein und Dein“ als Ausgangspunkt der Trennung der Regierungsund Justizsachen im aufgeklärten

\section{Absolutismus}

Das allgemeine Staatsrecht des 18. Jahrhunderts beschränkte den Begriff der Justizsache auf gegenseitige Streitigkeiten der Untertanen. Bei Heinrich Gottlieb Scheidemantel übten „Justizsachen [...] ihre Untersuchungen und Entscheidungen nur so weit aus, als die Gesezze des Landes das Mein und Dein der Untertanen neu bestimmen." ${ }^{181}$ Die Justiz konzentrierte sich damit auf den Schutz der Rechte der Untertanen in ihren Privatverhältnissen mit anderen Untertanen. Wesentlicher Gegenstand der obersten Justizkompetenz ist damit "die Entscheidung der Streitigkeiten zwischen den Bürgern unter sich. ${ }^{\prime 182}$

Damit beantwortete sich die Frage, ob eine Justizsache vorlag, nach dem Gegenstand der juristischen Auseinandersetzung. Waren die Untertanen in ihren Rechten untereinander betroffen, war eine Justizsache gegeben. Denn die Ziviljustiz entschied die „Streitigkeiten, welche über die Rechte einzelner unter und gegen einander und die Art der Ausübung derselben entstehen können“. ${ }^{183}$ Die Justizkompetenz blieb damit auf Zivilstreitigkeiten beschränkt, die allerdings auch über staatliche Maßnahmen urteilen konnte. ${ }^{184}$ Dann aber nur insoweit, als „dabei nicht in

181 SCHEIDEMANTEL, Staatsrecht nach der Vernunft 2, 329.

182 MADIHN, Grundsätze des Naturrechts 2, 79; DARJES, Commentatione 6: „Principium ex quo omnia, quae ad lurisprudentiam pertinent, ducuntur, est: neminem laedas, suum cuique tribuas."; MARTINI, Allgemeines Recht der Staaten 53: „Der Regent hat das Recht über die Streitigkeiten der Unterthanen zu urtheilen und diesselben zu entscheiden."

183 BERG, Handbuch 1, 133; vgl. BoB, System der Polizeywissenschaft 135: „Gegenstände, die sich auf das gegründete Recht eines Dritten beziehen, gehören in die Gränzen der bürgerlichen Jurisprudenz." ${ }^{184}$ LiebensteIn, Cammer- und Justiz-Collegien 46.
Erwägung gezogen wird, ob eine solche Verfügung dem Staate vor oder nachtheilig seye; denn dieses liegt der Cammer zur Untersuchung ob," also den Polizeikollegien. ${ }^{185}$

Diese Beschränkung der Justizsachen auf das Mein und Dein der Untertanen war Ausgangspunkt für die Trennung der Regierungs- und Justizsachen im aufgeklärten Territorialstaat des 18. Jahrhunderts. „Man sondert die Geschäfte von einander, und übergiebet einigen Collegiis die den größten Theil des Regiments ausmachende Handhabung der Gerechtigkeit, andern aber die Regierungssachen, wodurch dann zwar eine schleunigere und bessere Erledigung der Geschäfte, zugleich aber auch mancher Streit darüber veranlasset wird, was eigentlich Regierungs- und Justizsachen sind?" 186 Die derart motivierte Trennung der Regierungs- und Justizsachen führte zur Diskussion der Verschiedenheit von Regierung und Gerichtsbarkeit. So formuliert Struben unter dem Titel „Gründlicher Unterricht von Regierungs- und Justizsachen; worin untersucht wird: Welche Geschäfte ihrer Natur und Eigenschaften nach vor die Regierungs- oder Justiz-Collegia gehören“ (1788): „Im engern Verstande aber, wenn die Landesregierung den Justizcollegiis, mithin die Regierungssachen den Justizsachen entgegen gesetzet werden, verstehet man durch jene die Geschäfte, so keine Gerichtliche Untersuchung und Richterlichen Spruch erfordern, sondern durch Gesetze, Verordnungen und Schlüsse, mehrentheils pro prudenti imperantium arbitrio, abgethan werden können." ${ }^{187}$ Der politische Wille des Landesherrn (pro prudenti imperantium arbitrio) ${ }^{188}$ entscheidet in Regierungssachen, und der vernunftbestimmte Normzweck der Gesetze in Justizsachen: „Jene mißt [...] nach Wohlfarth des Staats und der Unterthanen [...] diese [...] nach den

\footnotetext{
${ }^{185}$ Ebd. 46.

186 STRUBEN, Nebenstunden 3, 48.

187 STRUBEN, Gründlicher Unterricht 23.

188 Ebd. 23.
} 
Gesetzen und deren Verstande ab.“189 Diese Zuordnung fügt sich ein in den vom aufgeklärten Absolutismus angestrebten Gesetzesstaat, in dem der jeweilige Wille des Herrschers hinter den vernunftbestimmten Normzweck zurücktritt. 190

\section{b. Die Justizgewalt in der politischen Theorie des aufgeklärten Absolutismus}

Im ius publicum des aufgeklärten Absolutismus gehört die Justizgewalt zu den besonderen Hoheitsrechten des Regenten, ${ }^{191}$ d.h. zu den "mit der obersten Gewalt unzertrennlich verbundenen Rechten“. ${ }^{192}$ Diese Konzentration der Hoheitsrechte im Begriff der „obersten Gewalt" ist vor dem Hintergrund zu sehen, dass 1718 die erste deutsche Übersetzung von Lockes „Second Treatise of Government" (1689) erschienen ist und 1753 Montesquieus "L'esprit des Lois" (1748) in die deutsche Sprache übertragen wurde. Bis in die zweite Hälfte des 18. Jahrhunderts taucht Lockes Treatise jedoch nicht in den einschlägigen Juristischen Nachschlagewerken auf. ${ }^{193}$ Für Montesquieu ist das Bild nur auf den ersten Blick ein anderes: Montesquieu wird in der Literatur des 18. Jahrhunderts durchaus genannt. ${ }^{194}$ "Seine Idee einer Gewaltenverteilung ist in der deutschen Staatsphilosophie nach 1750 auch bekannt, nicht aber populär."195 Die meisten Staatsrechtler des 18. Jahrhunderts jedoch leh-

\footnotetext{
189 SIEBERS, Macht der Reichsstände 4f.

${ }^{190}$ WiLlOWEIT, Verfassungsgeschichte 197f.; zu Gliederungspunkt IV.3.a. vgl. MÜßIG, Recht und Justizhoheit 223ff.

${ }^{191}$ ACHENWALL, Staatsklugheit 26; SCHEIDEMANTEL, Allgemeines Staatsrecht 95ff., $145 \mathrm{ff}$.

${ }^{192}$ KLEIN, Grundsätze 255; vgl. auch von HertLein, Juridisch-Politischer Versuch 12.

${ }^{193}$ Dazu SEIF, Recht und Gerechtigkeit 125; Allgemein DREITZEL, Monarchiebegriffe 2, 633ff.

${ }^{194}$ FENSKE, Gewaltenteilung 923, 935; HERDMANN, Montesquieurezeption 16ff.; VIERHAUS, Montesquieu in Deutschland 403ff. Dazu jüngst MoHnhaupt, Einfluß, Wirkung und Funktion 1, 27ff.

${ }^{195}$ Dazu SEIF, Recht und Gerechtigkeit 126.
}

nen den Gedanken der Teilbarkeit der obersten Staatsgewalt ab. Der Regent vereinigt in seiner Person alle Staatsgewalt (plenitudo potestatis): das Majestätsrecht der Gesetzgebung, der Gerichtsbarkeit und der Regierung. Weder die erkennbare aristotelische Dreiteilung ${ }^{196}$ in beratende (gesetzgebende), exekutive und richterliche Tätigkeit noch die Ausübung durch unterschiedliche Staatsbedienstete bedeutet eine Teilung der drei selbständigen Gewalten: „Neque ipsi [principes] legislatoriam potestatem antiquis temporibus satis cognoverunt nec a potestate iudiciali illam sat distinxerunt," 197 vernehmen wir Johann August Reichardt in seiner "Jenaer Disseration" von 1769. Außerdem würde - nach der Ansicht von Heinrich Gottlieb Scheidemantel - die Wohlfahrt des Staats unter der Gewaltenteilung leiden, denn „einer würde des andern Absicht vereiteln, seine Macht entkräften. ${ }^{\prime 198}$

\section{c. Machtspruchkritik}

Selbst die Unterscheidung zwischen Regierungs- und Justizsachen in der ab 1750 einsetzenden Machtspruchkritik ${ }^{199}$ geht nicht von einer Trennung zwischen Regierungsgewalt und Justizhoheit aus. „Der Grund des Rechts, MachtSprüche $\mathrm{zu}$ ertheilen, wird aus der plenitudine potestatis, das ist, aus der Macht-Vollkommenheit derer Regenten hergeleitet, "200 formuliert

196 ARISTOTELES, Politik IV. Buch, Nr. 14, 1297b411298a3. Dazu auch TSATSOS, Lehre von der Gewaltenteilung 11, 13ff. Zur staatlichen Strukturierung der absolutistischen Herrschaftsgewalt in die drei Gewalten bei den rationalistisch-atomistischen Staatskonstrukteuren des 17. Jahrhunderts, vgl. KLUXEN, Lehre von der Gewaltentrennung $219 \mathrm{ff}$.

197 REICHARDT, Selecta de iure statuum provincialium 15.

198 SCHEIDEMANTEL, Staatsrecht nach der Vernunft 1, 161. Zu Gliederungspunkt IV.3.b. vgl. SEIF, Recht und Gerechtigkeit 225f.

${ }^{199}$ Zunächst nur für Entscheidungen der obersten Staatsgewalt in Zivilsachen, dann aber auch im Bereich der Strafrechtspflege (OGRIS, Machtspruch 126).

${ }^{200}$ MOSER, Kayserliche Macht-Sprüche 8f., § 5 . 
Johann Jacob Moser 1750 in seiner „Abhandlung von Kayserlichen Macht-Sprüchen In RechtsStaats- und Gemischten Sachen“. ${ }^{201}$ Auch David Georg Struben geht 1761 in den "Nebenstunden, 13. Abhandlung: Von Regierungs- und Justizsachen", von der Vereinigung der Gewalten beim Monarchen aus. ${ }^{202}$ Mit dieser Prämisse stimmt auch der Großkanzler Friedrichs, Philipp Joseph Pandin de Jariges, in seinen "Réflexions philosophiques et historiques, d'un jurisconsulte, adressées à son ami à Turin sur l'ordre de la procedure, et sur les décisions arbitraires et immédiates du Souverain" (1765) überein. ${ }^{203}$ Ebenso begründet Johannes Ulrich von Cramer in seinem "Systema Processus Imperii seu Superiorum Augustissimorum Tribunalium" 1768 die kaiserliche Evokations- und Machtspruchbefugnis mit der obersten Gerichtsbarkeit des Kaisers. ${ }^{204}$ Wigulaeus Freyherr von Kreittmayr formuliert 1770 in seinem „Grundriß des Allgemeinen, Deutsch- und Bayrischen Staatsrechtes": „Er bleibt aber nichts destoweniger allzeit noch fons omnis jurisdictionis, und das diesfällige Majestätsrecht oder regale äussert sich gar sichtbar theils in der Subordination aller untergebenen Obrigkeiten, theils in den reservatis, womit ihnen die Jurisdiction nur in gewisser Maas beygelegt ist, sonderbar aber in dem jure recipiendi appellationes, supplicationes vel revisiones, und dem sowohl in civilibus als

\footnotetext{
${ }^{201}$ Moser behandelt die kaiserlichen Machtsprüche und ist daher für die Darstellung des aufgeklärtabsolutistischen Territorialstaats nur indirekt aussagekräftig. Vgl. zu Johann Jacob Moser BlunTSCHLI, Geschichte 451ff.; BussI, Johann Jacob Moser 375ff.; MoHL, Geschichte 2, 51ff.; LAUFS, Moser 284ff.; RENZ, Mosers staatsrechtlich-politische Vorstellungen 27ff.; RÜRUP, Johann Jacob Moser 31ff.; ScHÖMBS, Staatsrecht Johann Jakob Mosers 17ff.; STOLLEIS, Geschichte des öffentlichen Rechts 1, 258ff.; WALKER, Moser and the Holy Roman Empire 5ff.

${ }^{202}$ STRUBEN Nebenstunden 3, 13. Abhandlung: Von Regierungs-und Justizsachen 43, 51, 68. Vgl. zu David Georg Struben FRENSDORFF, Strube.

${ }^{203}$ PANDIN DE JARIGES, Réflexions 21.

${ }^{204}$ CRAMER, Systema Processus Imperii 4, § 10.
}

criminalibus offenstehenden Recurs ad principem, item in den Machtsprüchen, welche er ex plenitudine potestatis [...] ergehen lassen kann. ${ }^{205}$ Die Trennung der Regierungs- und Justizsachen lässt nach Jacob Gottlieb Siebers „Abhandlung von der Macht der Reichsstände und Gerichtsherrn Selbst Recht zu sprechen“ (1773) die Machtvollkommenheit des Landesherrn unberührt, eine Rechtssache selbst durch Machtspruch zu entscheiden: „Es ist wahr, [...] daß die Absonderung der Regierung und der Gerichtshöfe sowol in den Gesetzen als durch das Herkommen bestätiget, und das Volk berechtigt ist, deren Verbindung zu verhindern; allein daraus folget doch nicht die unbedingte Nothwendigkeit, daß die höchste Gewalt sich der Macht begeben habe, in einzelnen Fällen selbst Recht zu sprechen, oder es durch ihren Staatsrath thun zu lassen. “206

Die Bezeichnung der Entscheidung eines Rechtsfalls oder Vorgaben für das entscheidende Gericht durch den Monarchen als Machtspruch

${ }^{205}$ KREITTMAYR, Grundriß 1, 20f. Vgl. zu Wigulaeus Freyherr von Kreittmayr BAUER, Kreittmayr 17ff.; BECHMANN, Kanzler Kreittmayr 31ff.; DEMEL, Adelsrecht 151ff.; HARTIG, Reform der prozeßleitenden Grundsätze 10ff.; KALB, Studien zur Summa Stephans von Tournai 12ff.; KREITMAIR, Staatsrechtliche Grundlehren 21ff.; REINGRUBER, Abhandlungen 11ff.

${ }^{206}$ SIEBERS, Macht der Reichsstände 27: „§32. Es ist wahr, daß die Gleichheit der Partheyen oftmals leidet, daß die eine Parthey oftmals Gefahr laufe, daß die Absonderung der Regierung und der Gerichtshöfe sowohl in den Gesetzen als durch das Herkommen bestätiget, und das Volk berechtigt ist, deren Verbindung zu verhindern; allein daraus folget doch nicht die unbedingte Nothwendigkeit, daß die höchste Gewalt sich der Macht begeben habe, in einzelnen Fällen selbst Recht zu sprechen, oder es durch ihren Staatsrath thun zu lassen.“ Ebd. 18: „§ 24. Allein die regierende Macht ist die Quelle aller Gerichtsbarkeit, und es folget daraus [...] gar nicht, daß sie des Rechts, sie in einzelnen Fällen selbst auszuüben, oder durch jemand anderst ausüben zu lassen, sich gänzlich begeben habe." Vgl. zu Jacob Gottlieb Siebers MeusEL, Lexikon 13, 148ff.; RÖTGER, Nekrolog 4, 34f.; WEIDLICH, Biographische Nachrichten 2, $42 \mathrm{f}$. 
(sententia ex plenitudine potestatis) ist gerade in der Charakterisierung der landesherrlichen Stellung mit der plenitudo potestatis begründet, aus der sich das besondere Gewicht der landesherrlichen Streitentscheidung herleitet. ${ }^{207}$ Denn kraft seiner Gesetzgebungsgewalt konnte der Landesherr eine gerechte Entscheidung auch dadurch treffen, indem er ein neues Gesetz schuf. ${ }^{208}$ Das Selbstverständnis des aufgeklärten Monarchen als „erster Diener des Staates“ schließt die automatische Wertung des Machtspruchs als willkürliche Einzelfallentscheidung aus. In der Regel war sich der Landesfürst bei der persönlichen Ausübung des Richteramtes seiner Verantwortung als oberster Richter für die Wahrung und Ausübung einer guten Justiz wohl bewusst. ${ }^{209}$ Der Unterschied zum Rechtspruch (Gerichtsspruch) als der im Gericht institutionalisierten Entscheidung von Rechtsgelehrten im Rahmen eines justizförmigen Verfahrens wird zunächst nur formal institutionell verstanden. ${ }^{210}$ Diese inhaltliche Neutralität der anfänglichen Machtspruch-Terminologie, frei von der Idee des Willküraktes, wird dadurch bestätigt, dass der Begriff Machtspruch erstmals 1719 von Heinrich von Cocceji in seiner Schrift "Prodromus Justitiae gentium" verwendet wird, ${ }^{211}$ also weit vor der 1750 einsetzenden Machtspruchkritik. Der Coccejische Begriff weist nur auf eine Funktion der obersten Rechtsmacht hin ${ }^{212}$ und steht im Zusammenhang mit der schon seit Anfang des 18. Jahrhunderts debattierten Frage, „ob und was vor eine Plenitudo Potestatis oder

207 SCHMIDT, Rechtssprüche und Machtsprüche 6.

208 Ebd. 5.

${ }^{209}$ Beispiele zu den Preußenkönigen ebd. 7f.

210 OGRIS, Machtspruch 126; DERS., Kabinettsjustiz 515. Gegen einen inhaltlichen Gegensatz auch SCHMIDT, Rechtssprüche und Machtsprüche $3 \mathrm{f}$.

211 CoCCEJI, Liber Ad Illustriationem 23. Heinrich von Cocceji war der bedeutendste Vermittler von Grotius (SCHNEIDER, Wissenschaftliche Beziehungen 90ff.; STOLLEIS, Geschichte des öffentlichen Rechts 1, 247).

212 Ähnlich auch BUSSI, Geschichte der Machtsprüche 52. vollkommene Gewalt bey einem Fürst sich befinde." ${ }^{213}$ Machtspruch ist demnach eine Entscheidung des Inhabers der obersten Staatsgewalt. Darunter fällt auch die Entscheidung des Landesherrn durch einen Kommissar. ${ }^{214}$ Denn der Kommissar verkörpert den Grundsatz, dass der absolute Monarch stets berechtigt ist, selbst in jeder den Staat oder das Gemeinwohl betreffenden Sache tätig zu werden.215 Er personifiziert daher den landesherrlichen Machtanspruch des obersten Gerichtsherrn (Fons Jurisdictionis in suo territorio), ${ }^{216}$ die Entscheidung einzelner Prozesse an sich zu ziehen.

Die Übertragung der Rechtsprechung auf rechtsgelehrte Richter sondert die Justizhoheit nicht aus der einheitlichen landesherrlichen Majestät auf unabhängige Verfassungsorgane aus: „Es mag nun ein freyer Wille oder eine Nothwendigkeit seyn, das Gericht durch andere verwalten zu lassen; so findet man eben darinn den Unterschied der Gerichtsbarkeit und deren Ausübung, des Gerichtsherrn und dessen, so sie Nahmens seiner ausübet. Jener bleibt allemal der Herr des Gerichts und der Gerichtsbar-

\footnotetext{
${ }^{213}$ ERTEL, Schau-Bühne 32f.

214 ,Wenn es anderst angehet, sich der Analogie zu bedienen; so wird der Landesherr befugt seyn, in denen Rechtssachen, die er überhaupt vor sein Cabinett oder seinen Geheimen-Rath zu ziehen berechtiget ist, auch Commissionen zu erkennen. Stehet ihm aber jenes nicht zu; so kann ihm auch dieses nicht zukommen, wenn nicht ein anderes in den Landesgesetzen enthalten ist. Denn wenn der Landesherr überhaupt versprochen und erkläret hat, den Lauf der Rechtspflege durch keine Rescripte, Mandate, Inhibitionen zu hemmen: so kann er auch nicht die Macht haben, ihn durch Commissionen zu ändern oder zu hindern, oder aufzuhalten.“ (SIEBERS, Macht der Reichsstände 221).

${ }^{215}$ WILLOWEIT, Verfassungsgeschichte 160.

216 „Ceterum vero quilibet Status est Fons Jurisdictionis in suo territorio." (PÜTTER, Elementa Iuris Germanici $\S 799$, S. 253. Vgl. auch DeRS., Anleitung 2, 43f.; DERS., Beyträge 1, 11.
} 
keit. “217 Die verschiedenen Hoheitsrechte können durch unterschiedliche Staatsbedienstete ausgeübt werden, dies bedeute aber noch nicht Trennung der Hoheitsrechte von der höchsten Gewalt.218 Ausgehend von der einheitlichen monarchischen Staatsgewalt sind die Richter "Gehülfen der Regierung“, 219 ",welche von dem Staate mit einem Theile der vollziehenden Gewalt bekleidet ${ }^{\text {“220 }}$ sind.

Wegen der unbeschränkten Justizgewalt ist die Machtspruchkritik auch nicht durch Notwendigkeit der Gewaltenteilung gegen Machtmissbrauch motiviert, sondern vielmehr mit der Belastung des Monarchen durch die Regierungsgeschäfte ${ }^{221}$ oder mit dem Mangel an ,juristischer Fachkenntnis", "Kaltblütigkeit“ und "Zeit".222 Die Zuständigkeit des ordentlichen Richters beruht auf einer rein arbeitsteiligen, nicht konstitutionellen Begrenzung der landesherrlichen Gerichtsbarkeit: „Wenn aber der Fürst die Sache selbst entscheidet, so muß er entweder seine Zeit der Regierung des Ganzen entziehen, oder sich an einer flüchtigen Untersuchung begnügen. Deswegen ist es wohl für die streitenden Theile kein geringer Trost zu wissen, daß 10, 20, 30 auch wohl mehrere in dergleichen Geschäften geübte Personen sich mit ihrer Rechtssache beschäftigen werden," formuliert Ernst Ferdinand Klein. ${ }^{223}$ Auch für Theodor

\footnotetext{
${ }^{217}$ SIEBERS, Macht der Reichsstände 9f, § 13; Vgl. auch ebd. 18: „§24. Allein die regierende Macht ist die Quelle aller Gerichtsbarkeit, und es folget daraus ... gar nicht, daß sie des Rechts, sie in einzelnen Fällen selbst auszuüben, oder durch jemand anderst ausüben zu lassen, sich gänzlich begeben habe."

218 SCHEIDEMANTEL, Staatsrecht nach der Vernunft 1, 157.

${ }^{219}$ GÖNNER Commentar LV. Vgl. auch SIEBENPFEIFFER, Gerichtsverfassung des Rheinkreises 48ff.

${ }^{220}$ PuCHTA, Grenzen des Richteramtes 10.

${ }^{221}$ PUCHTA, Landgerichte in Bayern 96ff.

${ }^{222}$ GÖNNER Handbuch 1, 9f.; DERS., Deutsches Staatsrecht $474 f$.

${ }^{223}$ KLEIN, Beurtheilung 391, 394; Vgl. zu Ernst Ferdinand Klein: BRÜNKER, Ernst Ferdinand Klein 19ff.;
}

(von) Schmalz 224 beruht die Zuständigkeit des ordentlichen rechtsgelehrten Richters auf der landesherrlichen Beauftragung mangels eigener Rechtskenntnis ${ }^{225}$ und -ausbildung ${ }^{226}$ aus bloßen Praktikabilitätserwägungen wie der Arbeitsüberlastung des Regenten.227 Die Gewaltenteilungsidee ist für ihn eine "leere Täuschung“. 228 Von Gönner zieht in Betracht, „wie viel Kenntnis [erforderlich ist], um sich zu einem wahren Justizmann zu bilden, wieviel Kaltblütigkeit, um es zu seyn, wie viel Zeit, um bey einzelnen Streitigkeiten dem Umfang seiner Richterpflichten genug $\mathrm{zu}$ thun, erfordert werde, ${ }^{\prime 229}$ und stellt fest, „daß diese Erfordernisse weder bey einem

FIORILLO, Zwangsapparat oder Wertordnung? 197ff.; Hellmuth, Carl Gottlieb Suarez und Ernst Ferdinand Klein 63ff.; HolzHAUER, Klein, 866ff.; KleEnSANG, Ernst Ferdinand Klein 10ff.; DERS., Konzept der bürgerlichen Gesellschaft 17ff.; TEICHMANN, Klein.

224 SCHMALZ, Teutsches Staats-Recht 251, §393: „daß in einem cultivirten Lande nur gelehrte Richter die richterliche Gewalt werden leiten können, und Recht sprechen müssen."

${ }^{225}$ Vgl. auch STRUBEN, Nebenstunden 5, 438: „Es bleibet also immer wahr, daß die gemeine Wohlfarth eine sorgfältige Absonderung der Regierungs- und Justizsachen erfordert, mithin daß die letztern den Gerichtshöfen zu überlassen sind. Nachdem das Rechtsprechen zu einer Kunst worden, die niemand gebührend üben kan, ohne sie mühsam erlernet zu haben, ist es nothwendig, jenes den Rechtsgelehrten zu überlassen. Wenn ein König selbst mit im Gerichte votirte, so würden ihm schwerlich die Beisitzer widersprechen, und eines Irthums zu überführen suchen, mithin behinderte solches die erforderliche Erörterung der Sachen."

${ }^{226}$ SCHMALZ, Teutsches Staats-Recht 251, § 393.

${ }^{227} \mathrm{Zu}$ diesen Praktikabilitätsargumenten vgl. auch OGRIS, Machtspruch 127.

${ }^{228}$ SCHMALZ, Natürliches Staatsrecht 219. Vgl. auch DERS., Handbuch der Rechtsphilosophie 284f.: „leerer Traum und gefährliche Theorie".

${ }^{229}$ GÖNNER, Handbuch 1, 474f. Vgl. zu Nicolaus Thaddäus Gönner: BOMSDORF, Prozeßmaximen und Rechtswirklichkeit 10ff.; HOLZHAUER, Gönner 1752ff.; JÄCK, Gönners Biographie 1ff.; KOCH, Gönners Staatslehre 15ff.; WEHNER, Gönner 12ff. 
Fürsten, noch bey seinem Cabinet immer erfüllt werden könnten.“230

Trotz Koinzidenz des Erscheinens von Montesquieus Geist der Gesetze 1748 und der 1750 einsetzenden Machtspruchkritik lässt sich demnach keine Rezeption der Gewaltenverteilung Montesquieus nachweisen.231 Erkennbar ist allenfalls das Interesse am Thema der Verschiedenheit von Regierungs- und Justizsachen, ${ }^{232}$ angeregt durch die eifrig zitierten montesquieuschen Textvorlagen aus dem VI. Buch, 5. und 6. Kapitel „De L'Esprit des Lois“ (1748). ${ }^{233}$ Außer bei Jacob Gottlieb Siebers und David Georg Struben finden sich Zitate auch noch bei Karl Friedrich Häberlin. ${ }^{234}$

Eine inhaltliche Auseinandersetzung mit diesen Passagen aus dem Geist der Gesetze gegen die unmittelbare Ausübung der Justizhoheit durch

${ }^{230}$ GÖNNER, Handbuch 1, 10, 14.

${ }^{231}$ Vgl. z.B. CRAMER, Wetzlarische Nebenstunden 70f., § 36; PÜTTER, Opuscula rem iudiciariam IX, 342f., § II; A.A. SCHMIDT, Rechtssprüche und Machtsprüche 8. ${ }^{232}$ SIEBERS, Macht der Reichsstände 4f: „§7 Die Geschäfte der Regierung und die Geschäfte der Gerichtsbarkeit sind mächtig von einander unterschieden."

233 "§ $\$ 2$. Der Herr von Montesquieu in seinem in vielem Betracht vortrefflichen Buche de l'esprit des lois hält es in monarchischen Staaten vor nothwendig, daß der Monarch und sein Geheimer Staatsrath mit der Entscheidung einzelner Fälle sich nicht abgeben, sondern selbige lediglich den zur Verwaltung der Justiz gesetzten Collegien überlassen müsse. Ja er behauptet, daß eine Monarchie aufhöre, es zu seyn, wenn solches geschähe. Ich will seine Worte aus dem 6ten und 7ten Capitel des sechsten Buchs selbst hersetzen." [Es folgt das Montesquieu-Zitat aus VI,5, nicht wie von Siebers irrtümlich angegeben aus VI,6] (SIEBERS, Macht der Reichsstände 23f). Mit VI,6 belegt Siebers die Verschiedenheit von Regierung (Minister) und Gerichtsbarkeit (Richter) (Ebd. 24).

${ }^{234}$ HÄBERLIN, Handbuch des Teutschen Staatsrechts § 261, S. 302 f: „Der scharffsinnige Montesquieu sagt in seinem Buche über den Geist der Gesetze: in den despotischen Staaten darf der Fürst richten, nicht so in monarchischen: sonst würde die Verfassung zerstöret, die Form der gerichtlichen Entscheidung aufgehoben, die Gemüther aber mit bleichender Furcht erfüllt werden." den Herrscher selbst (VI. Buch, 5. Kapitel) oder durch Regierungsmitglieder (VI. Buch, 6. Kapitel $)^{235}$ findet dagegen nicht statt. Montesquieus Gedanke der Vermittlung der Justizhoheit durch ordentliche Justizbeamte wird von Jacob Gottlieb Siebers und Karl Friedrich Häberlin nicht aufgegriffen. David Georg Struben paraphrasiert zwar in der „Abhandlung Von Regierungsund Justizsachen" aus den "Nebenstunden“ die Montesquieusche Textvorlage in VI,5 und $\mathrm{XI}, 6,236$ distanziert sich aber ausdrücklich von jeder Einschränkung der monarchischen Justizhoheit: „In Teutschland hat jedoch weder zu ältern noch zu neuern Zeiten es der Freyheit Abbruch gethan, daß mit den Fürsten, und denjenigen, welche sie in Regierungs-Sachen zu Rath zogen, die Gerichts-Höfe vielfältig besetzet worden. “237 Und Johann Jacob Moser bezeichnet die Relevanz von Montesquieus Gedanken der Gewaltenverteilung für das Verbot von Machtsprüchen explizit als "null und nichtig“.238 Allenfalls der Nationalökonom Johann Heinrich Gottlob von Justi rezipiert in seiner 1760 erschienenen Abhandlung von "Natur und Wesen der Staaten als die Quelle aller Regierungswis-

${ }^{235}$ Die unvermittelte Ausübung der Justizhoheit durch den Herrscher selbst oder durch politisch Abhängige ist Despotie: „Dans les États despotiques, le prince peut juger lui-même. Il ne le peut dans les monarchies: la constitution seroit détruite, les pouvoirs intermédiaires dépendants, anéantis." (MonTESQuieu, De l'Esprit des Lois 314).

236 STRUBEN, Nebenstunden 3, paraphrasiert VI,5 und XI,6 De L'Esprit des Lois: „eine solche Vereinigung könne mit der Freyheit nicht bestehen; die rechtliche Entscheidungen würden gar leicht willkührlich, mithin liefe das Leben, die Freyheit und Güter der Unterthanen Gefahr, wenn diejenigen, welche die höchste Gewalt in Händen haben, sich auf den RichterStuhl setzten. Eben deswegen sey in den mehresten Europäischen Königreichen die Regierungs-Form nicht despotisch, weil man in selbigen die RechtsHändel durch Unterthanen erörtern ließe. Ein Fürst müsse Richter bestellen, nicht aber selbst richten." 237 STRUBEN, Nebenstunden 3, 44.

${ }^{238}$ Moser, Kayserliche Macht-Sprüche 15, § $9 \mathrm{aE.}$ 
senschaften und Gesetz" die Montesquieuschen Staatsgrundgesetze, die nach II, 4 l'Esprit de Lois die gemäßigte Monarchie ausmachen: „Grundregeln, nach welchen man sich versetzt, [...], daß der Regent und seine Ministers niemals die Hände in die Verwaltung und den ordentlichen Verlauf der Gerechtigkeit einschlagen wollen [...]; solche Grundregeln, sage ich, werden die uneingeschränkte Gewalt allemal auf eine sehr edle und vorzügliche Weise mäßigen und zur Wohlfahrt des Staates die besten Wirkungen hervorbringen. ${ }^{\prime 239}$

Die Sekundärliteratur bejaht nicht nur einen nicht nachzuweisenden - Zusammenhang zwischen Montesquieu und den Machtspruchkritikern, sondern verkennt auch die Interpretation von Montesquieus Kritik an der unmittelbaren Ausübung der Justizgewalt durch den Herrscher selbst oder durch Kommissare. ${ }^{240}$ Unvermittelter Machtgebrauch durch den Herrscher selbst oder durch Kommissare beeinträchtigt die Freiheit. ${ }^{241}$ Die Mittelbarkeit der Herrschergewalt entspricht der Mäßigung der Staatsgewalt, wodurch politische Freiheit erst

\footnotetext{
${ }^{239}$ JUSTI, Natur und das Wesen der Staaten 94. Vgl. auch ebd. 92): „Wenn demnach auch eine Regierung das allervollkommenste Recht zur uneingeschränkten Gewalt hat, so erfordert es die Natur der Sache, die Billigkeit und die Wohlfahrt des Staates, die mit ihrer eigenen genauso verbunden ist, daß sie sich selbst mäßiget und ihre Gewalt aus eigener Bewegung einschränke." Träger eines politischen Gemeinwesens ist bei Justi nicht mehr der Staat, verkörpert im monarchischen Souverän, sondern die Vielzahl der den Staat bildenden gesellschaftlichen Gliederungen. Dazu auch DreITZEL, Absolutismus und ständische Verfassung 100ff.; PAHLOW, Justiz und Verwaltung 58. Zu Montesquieus Staatsgrundgesetzen vgl. SEIF, Mißverstandener Montesquieu 156.

${ }^{240}$ SCHMIDT, Rechtssprüche und Machtsprüche 8; DIESTELKAMP, Reichskammergericht und Rechtsstaatsgedanke 1f., 23, einschränkend jedoch in Anm. 29, wo er auf die ausschließlich reichsrechtliche Argumentation von Schick und Cramer hinweist.

${ }^{241}$ MontesQuieu, De l’Esprit des Lois 314.
}

möglich wird. ${ }^{242}$ Dieser Gedanke der Mäßigung der Justizhoheit durch ordentliche Justizbeamte als selbständige Zwischengewalten ist im Zusammenhang zu sehen mit Montesquieus Ideal der monarchischen Mischverfassung und beruht daher nicht auf einer konstitutionellen Gewaltentrennung. ${ }^{243}$

Aufgenommen wird jedoch Montesquieus Herrschaft der Gesetze. Der Gesetzesstaat steht entsprechend der vorrangigen Herrschaftsfunktion der Gesetzgebung für den Ausbau der Territorialstaaten und entsprechend den systematischen Deduktionen des an den deutschen Universitäten gelehrten Vernunftrechts - im Mittelpunkt der aufgeklärten Diskussion. Seit der Jahrhundertmitte wurden daher in den deutschen Territorialstaaten Gesetzgebungsvorhaben in Angriff genommen, deren Ziel die systematisch angelegte Regelung zusammengehöriger Rechtsmaterien in umfassenden Kodifikationen war. ${ }^{244}$ Ein neues Streben nach Rechtssicherheit deutete sich an, indem sich die Idee des Rechts untrennbar mit dem rational-zweckorientierten und ordnungsgemäß publizierten Gesetz verbindet. Dieser Primat der Gesetzgebung hat ein neues Verständnis der Richterentscheidung zur Folge. Der Rechtsspruch eines an das Gesetz gebundenen Beamten unterscheidet sich jetzt nicht mehr nur formal-institutionell, sondern auch inhaltlich vom Machtspruch des in seiner

${ }^{242}$ Politische Freiheit ist für Montesquieu die Mäßigung bei der Ausübung der souveränen Gewalt, unabhängig von der Regierungsform: „La liberté politique ne se trouve que dans les gouvernements modérés" (Montesquieu, De 1'Esprit des Lois 395). Die Freiheit ist damit für Montesquieu keineswegs direkt von der Regierungsform abhängig. Auch Republiken wie Venedig können tyrannisch sein. Zum ständischen Freiheitsbegriff Montesquieus vgl. BÖCKENFÖRDE, Gesetz und gesetzgebende Gewalt 30; SEIF, Mißverstandener Montesquieu 152f.

${ }^{243}$ Zur Diskussion der monarchia mixta in der deutschen Staatsrechtslehre vgl. DREITZEL, Monarchiebegriffe 1, 99ff.

${ }^{244}$ Dazu auch BussI, Geschichte der Machtsprüche 56. 
Machtfülle (plenitudo potestatis) allein Gott verantwortlichen Landesherrn. Der inhaltliche Gegensatz zwischen gesetzesgemäßer Richterentscheidung und politischer Kabinettsentscheidung war aus der Taufe gehoben. Der vernunftbestimmte Normzweck gilt für Justizsachen, ${ }^{245}$ der politische Wille des Landesherrn ist für Regierungssachen maßgeblich. ${ }^{246}$

\section{d. Vorrang des vernunftbestimmten}

\section{Normzwecks vor dem landesfürstlichen} Herrscherwillen im aufgeklärten Gesetzesstaat

Der Vorrang des vernunftbestimmten Normzwecks vor dem Herrscherwillen im aufgeklärten Gesetzesstaat bahnt die allmähliche terminologische Verschiebung vom Machtspruch zur Kabinettsjustiz an. ${ }^{247}$ Bei Betroffenheit von landesherrlichen Interessen erregt der Machtspruch den Verdacht der Parteilichkeit ${ }^{248}$ oder macht den Landesherrn zum Richter in eigener Sache. ${ }^{249}$ Überdies würden die Untertanen nicht gleichbehandelt, wenn des einen Rechtssache vom Landesherrn selbst, des anderen Anliegen aber von den ordentlichen Gerichten entschieden wird. So ist es für Jacob Gottlieb Siebers „eine Art der Ungleichheit die Sache des einen Unterthanen anzunehmen, und den anderen damit an die ordentlichen Gerichte zu verweisen [...] des Herrn Wille, daß der Beklagte oder der

${ }^{245}$ SIEBERS, Macht der Reichsstände 4f: „Jene mißt [...] nach Wohlfarth des Staats und der Unterthanen [...] diese [...] nach den Gesetzen und deren Verstande ab."

${ }^{246}$ STRUBEN, Gründlicher Unterricht 23: „pro prudenti imperantium arbitrio“; zu Gliederungspunkt IV.3.c. vgl. MÜßIG, Recht und Justizhoheit 226-232.

247 OGRIS, Machtspruch 127; DERS., Kabinettsjustiz 517; Dazu auch RegGe, Kabinettsjustiz in BrandenburgPreußen 13ff.; OGOREK, Machtspruchmysterium 82ff. Kritisch DiESTELKAMP, Reichskammergericht und Rechtsstaatsgedanke 1. Nach PLATHNER, Richterliche Unabhängigkeit 35ff., hat zuerst SCHICK, Tractatus Iuris Publici, den Begriff Kabinettsjustiz gebraucht.

${ }^{248}$ SIEBERS, Macht der Reichsstände 13.

${ }^{249}$ Ebd. $42 \mathrm{ff}$.
Kläger in der Kürze zu seinem Rechte gelange, [...] ist auch keine Ursache, warum der eine oder der andere vor so vielen hunderten und tausenden den Vorzug habe. Oder will die regierende Macht und ihr Geheimer Staatsrath [...] die Sachen, welche sich leicht und in der Kürze erledigen lassen, vornehmen und entscheiden, warum nimmt man denn nicht alle Sachen von der Art an, und warum läßt man dem einen und dem andern diesen Vorzug angedeyhen, tausend anderen aber nicht? Die gleiche Gerechtigkeit, die gleiche Liebe und Gnade, woran doch alle Bürger des Staats ein gleiches Recht haben, verschwinden, und es ist natürlich, daß das Vertrauen des andern Theils und aller anderen Unterthanen, die nicht eines gleichen Gehörs theilhaftig werden, abnehme und in eine Art des Misvergnügens sich verwandele. Hat der Kläger bey seinem Gesuche die Absicht, in der Kürze durchzukommen: so hat der Beklagte, der sich an die regierende Macht wendet, die Absicht, sich dadurch seinen Verbindlichkeiten $\mathrm{zu}$ entziehen, oder Einwendungen gültig zu machen, die vielleicht sonst nach der Natur des Prozesses nicht zulässig sind. $\mathrm{Zu}$ geschweigen, daß oft politische Gründe vorhanden sind, dem einen oder dem andern zu liebkosen, wenigstens Nachsicht gegen ihn zu haben. Wo bleibt aber sodenn die Gleichheit, die Gefährtin der Gerechtigkeit!“250 Fehlerhafte Immediateingaben der Supplikanten ${ }^{251}$ oder fehlerhafte juristische Prü-

\footnotetext{
250 Ebd. 10ff.

${ }^{251}$ Scharf kritisiert Jariges das Supplikenwesen als Gefahr für die aufgeklärt-absolutistische Friderizianische Justizorganisation: "Ces exçellents arrangements, cet ordre, cette précision, cettte promtitude de la Procédure, n'empêchent pas cependant, que Sa Majesté ne soit importunée d'une foule de Plaintes, E qu'il n'y ait des gens qui pour se soustraire à tous les Tribunaux, osent lui demander des décisions immédiates." (PANDIN DE JARIGES, Réflexions 20ff.). Zum Supplikenwesen: PrESS, Calvinismus und Territorialstaat 43; HÜLLE, Supplikenwesen in Rechtssachen 194ff.
} 
fungen ${ }^{252}$ können zur materiellrechtlichen Ungerechtigkeit eines Machtspruchs führen. Ungeachtet seiner Justizhoheit wird ein aufgeklärter Monarch nicht als oberster Richter fungieren, um sich nicht der Gefahr ungerechter Entscheidungen auszusetzen. Diesen Gedanken baut des Preußenkönigs Großkanzler Philipp Joseph von Jariges 1765 in seinen „Réflexions philosophiques et historiques, d'un jurisconsulte, adressées à son ami à Turin sur l'ordre de la procedure, et sur les décisions arbitraires et immédiates du Souverain" weiter aus: „Un Monarque qui regne sur des hommes libres, $\mathcal{E}$ qui les gouverne par les Loix, ne doit jamais faire la fonction de Juge, s'il l'entreprenoit, il s'exposeroit à des erreurs, à des surprises, à des injustices sans nombre. ${ }^{.253}$ Selbst der gerechte Machtspruch ist für de Jariges ungesetzlich, da er gegen die Herrschaft der Gesetze verstößt: „Les sentences, même les plus équitables des Souverains, sont illégales $\mathcal{E}$ contraires à la Constitution de l'Etat. Mais des décisions arbitraires $\mathcal{E}$ immédiates sont directement opposées à la Justice, à l'Ordre, aux Loix, elles ne doivent être connuëes que dans un Etat Despotique, E jamais dans une Monarchie." ${ }^{254}$ Mit der unmittelbaren Ausübung der Justizhoheit durch den Herrscher selbst entfallen in den Despotien die Förmlichkeiten des Verfahrens, die in den Monarchien Leben, Ehre, Eigentum, Freiheit und Unschuld sichern: „Dans des pays au contraire, gouvernés par des Monarques \& non par des Despotes, par des Loix, E non par le Caprice, où l'on fait de la vie, de l'honneur, des biens des Sujets, le cas que l'on doit, dans de telles Monarchies, dis-je, les

\footnotetext{
${ }^{252}$ Durch die Regierungsgeschäfte kann er nicht die notwendige Zeit und Sorgfalt für eine Richtertätigkeit ausüben: „Les affaires importantes, les grands intérêts d'un Royaume, ne lui [le Prince] laissent pas le tems nécessaire pour écouter, les contestations des Parties, examiner leurs prétensions, lire de longues discussions, consulter des Auteurs, fouiller dans de vieux Documents, E juger d'une affaire avec l'exactitude $\mathcal{E}$ le loisir que mérite son importance." (PANDIN DE JARIGES, Réflexions 22).

${ }^{253}$ Ebd. 21.

${ }^{254}$ Ebd. 22.
}

Formalités sont $\mathcal{E}$ l'appui de la liberté, E le rempart de l'innocence. “" 255 Die Anklänge an Montesquieus Herrschaft der Gesetze in den Monarchien (VI, 5 De l'Esprit des Lois) sind deutlich. ${ }^{256}$

Auch nach der inhaltlichen Umwertung des Machtspruchs als politische Kabinettsentscheidung in der aufgeklärten Justiztheorie bleibt der aufgeklärt-absolutistische Landesherr zum Machtspruch berechtigt, "als es utilitas vel necessitas publica erfordert", ${ }^{257}$ wenn es ",necesse est" ${ }^{\prime \prime} 258$ in "justa causa“, 259 "wenn die allgemeine Wohlfarth [...] Gefahr läuft“,260 zur „Erhaltung des

${ }^{255}$ Ebd. 7, 24: "formé d'idée de la Procédure E des arrangements qui sont l'appui de leurs droits $\mathcal{E}$ de leurs sureté." ${ }^{256}$ MonTESQuieu, De 1'Esprit des Lois 314: „Dans les États despotiques, le prince peut juger lui-même. Il ne le peut dans les monarchies: la constitution seroit détruite, les pouvoirs intermédiaires dépendants, anéantis. „on verroit cesser toutes les formalités des jugements: la crainte s'empareroit de tous les esprits; on verroit la pâleur sur tous les visages; plus de confiance, plus d'honneur, plus d'amour, plus de sûreté, plus de monarchie."

257 KREITTMAYR, Grundriß 20f.

258 PÜTTER, Elementa Iuris Germanici Privati 258, § 814 formulierte den Gedanken der obersten Gerichtshoheit, die bei Notwendigkeit unmittelbar selbst ausgeübt werden kann: „Haec potestas (iudiciaria) ab ipso quouis principe, ceu summo iudice exerceri potest; [...] Unde cognitio causae, quanta fieri potest, circumspectione praecedat, necesse est, eaque nec tam facile solius principis, quam adhibitio peritorum bonorumque virorum iudicio, institui potest." Vgl. zu Johann Stephan Pütter EBEL, Pütter aus Iserlohn 11ff.; LINK, Pütter 310ff.; MARX, Methode der Rechtsfindung 59ff.; MOHL, Geschichte 2, 425ff.; SCHRÖDER, Wissenschaftstheorie und Lehre 75ff.; STOLLEIS, Geschichte des öffentlichen Rechts 1, $312 \mathrm{ff}$.

${ }^{259}$ CRAMER, Systema Processus Imperii Sectio I, tit. I (De origine ac constitutione generali supremorum imperii tribunalium) 4 .

${ }^{260}$ SIEBERS, Macht der Reichsstände 49: „§55. Allein in diesen Fällen wird die Noth kein Gesetz kennen, und die höchste Macht nicht unterlassen dürfen, eine Rechtssache vor ihr Cabinett oder ihren Staatsrath zu ziehen, wenn die allgemeine Wohlfarth, das heißt der äusserliche oder innerliche Ruhestand eines Landes Gefahr läuft, oder sonst sehr misliche Folgen einem Lande bevorstehen." 
Wohls des Staates",261 "wenn der Fall von der Art ist, daß durch Verwaltung einer unpartheiischen Justiz der Staat der größten Gefahr ausgesetzt würde.“262 Selbst der Konstitutionalismus des 19. Jahrhunderts kennt den Machtspruch noch als ein Machtgebot, das sich auf das äußerste Recht des Staates stützt: „Wo die Ausübung des äußersten Rechts durch die Umstände [...] begründet ist, darf der Staatsoberherr unmittelbar oder in constitutionellen Staaten durch das verantwortliche gesamte Staatsministerium, mit Abweichung von den sonst abwendbaren gewöhnlichen Verhandlungsformen und Entscheidungsquellen und mit Hintansetzung der gerichtlichen Kompetenz die Entscheidung eines einzelnen Rechtsstreites oder einen Strafbefehl ertheilen oder, auf seinen Spezialbefehl, von anderen als richterlichen Staatsbehörden ertheilen lassen. Als bloßes Machtgebot heißt sie in dem eigentlichen Sinn Machtspruch. “263 Dieses äußerste Recht ist dann nicht mehr die Machtvollkommenheit (plenitudo potestatis) eines aufgeklärt-absolutistischen Landesherrn, sondern die äußerste Gewalt (potestas eminens) im Staatsnotrecht, ${ }^{264}$ vergleichbar mit der einer Billigkeitsentscheidung, welche Ausdruck herrschaftlicher Gerichtshoheit ist. ${ }^{265}$

\section{Schluss}

Tezners Plädoyer gegen das „rechtsstaatliche“ Missverständnis absolutistischer Verwaltungsund Justizreformen belegt eindrucksvoll die Kontinuitätslinien der historischen Verwal-

\footnotetext{
${ }^{261}$ HÄBERLIN, Handbuch des Teutschen Staatsrechts $479, \S 300$.

262 Ebd. 477, § 300.

${ }^{263}$ KLÜBER, Öffentliches Recht des Teutschen Bundes, $829, \S 553$.

${ }^{264} \mathrm{Zu}$ Gliederungspunkt IV.3.d. vgl. MÜßIG, Recht und Justizhoheit 233-236.

${ }^{265}$ Dazu ausführlich MÜßIG, Summum ius, summum iniuria 23-65.
}

tungsrechtspflege für die österreichische Justizgeschichte. Das Organisationsprinzip der Verstärkung der Gerichtssenate der Regierungen durch Kammerräte überlebte auch die Trennung der Justiz und Verwaltung unter Joseph II. Die mit dem Kammerprinzip abgesicherte Gleichsetzung von landesfürstlichem und öffentlichem Interesse entspricht dem aufgeklärten Absolutismus, welcher nach den von Tezner ausgewerteten Entscheidungen der obersten Justizstelle das Fürsteninteresse durchaus recht großzügig auf privatrechtliche Fragen von Untertänigkeitsprozessen ausdehnte.

\section{Korrespondenz:}

Univ.-Prof. Dr. Ulrike Müßig

Universität Passau

Lehrstuhl für Bürgerliches Recht sowie Deutsche und Europäische Rechtsgeschichte Innstraße 39 (Juridicum)

94032 Passau

ulrike.muessig@uni-passau.de 


\section{Abkürzungen:}

Siehe das allgemeine Abkürzungsverzeichnis: [http://www.rechtsgeschichte.at/files/abk.pdf]

\section{Literatur:}

Gottfried ACHENWALL, Die Staatsklugheit nach ihren ersten Grundsätzen (Göttingen 1774).

Ulrich ADAM, The political Economy of J.H.G. Justi (Bern 2006).

Sigmund ADLER, Die Organisation der Centralverwaltung unter Kaiser Maximilian I. (Leipzig 1886).

Dieter ALBRECHT, Ferdinand II., in: SCHINDLING, ZIEGLER, Kaiser der Neuzeit 125-141.

ARISTOTELES, Politik, IV. Buch, übersetzt und hg v. Olof GIGON (München 1986).

Hanns-Martin BACHMANN, Die naturrechtliche Staatslehre Christian Wolffs (=Schriften zur Verfassungsgeschichte 27, Berlin 1977).

Joachim BAHLCKE, Politische Funktionen kirchlicher Beziehungen: Ungarn und die Reichskirche, in: Dietmar WILlOWEIT, Hans LEMBERG (Hgg.), Reiche und Territorien in Ostmitteleuropa - Historische Beziehungen und politische Herrschaftslegitimation (= Völker, Staaten und Kulturen in Ostmitteleuropa 2, München 2006) 227-246.

Hermann BALTL, Gernot KOCHER, Österreichische Rechtsgeschichte, unter Einschluss sozial- und wirtschaftsgeschichtlicher Grundzüge. Von den Anfängen bis zur Gegenwart (Graz 2009).

Richard BAUER, Wigulaeus Xaverius Aloysius Freiherr von Kreittmayr 1705-1790. Ein Leben für Recht, Staat und Politik (München 1991).

Bertrand Michael BuchmanN, Hof - Regierung Stadtverwaltung. Wien als Sitz der österreichischen Zentralverwaltung von den Anfängen bis zum Untergang der Monarchie (Wien-München 2002).

Peter BAUMGART, Joseph II. und Maria Theresia, in: SCHINDLING, ZIEGLER, Kaiser der Neuzeit 249-276.

H.-J. BECKER, Pragmatische Sanktion, in: Adalbert ERLER, Ekkehard KAUFMANN (Hgg.), Handwörterbuch der deutschen Rechtsgeschichte, Bd. 3: List - Protonotar (Berlin 1984) 1864-1866.

August von BechmanN, Der churbayerische Kanzler Alois Freiherr von Kreittmayr (München 1896).

Nicolaus BECKMANN, Idea Juris statutarii et consuetudinarii stiriaci et austriaci cum jure romano collati in quantum singula cum illo conveniant et in quantum inde reoedant (Graecii 1688).
Thomas BeHME, Samuel von Pufendorf. Naturrecht und Staat. Eine Analyse und Interpretation seiner Theorie ihrer Grundlagen und ihrer Probleme (= Veröffentlichungen des Max-Planck-Instituts für Geschichte 112, Göttingen 1995).

Günther Heinrich von BERG, Handbuch des Teutschen Policeyrechts, Bd. 1 (Hannover 1799).

Hermann Ignaz BIDERMANN, Geschichte der österreichischen Gesammt-Staats-Idee 1526-1804, I. Abt.: 1526-1705 (Wien 1972).

Johann Kaspar BLUNTSCHLI, Geschichte der neueren Staatsrechtswissenschaft. Allgemeines Staatsrecht und Politik seit dem 16. Jahrhundert bis zur Gegenwart (München ${ }^{3} 1881$, ND Aalen 1990).

Franz Joseph BoB, Von dem Systeme der Polizeywissenschaft (Freiburg im Breisgau 21779).

Ernst-Wolfgang BÖCKENFÖRDE, Gesetz und gesetzgebende Gewalt. Von den Anfängen der deutschen Staatsrechtslehre bis zur Höhe des staatsrechtlichen Positivismus (=Schriften zum öffentlichen Recht 1, Berlin 1958).

Justus Henning BOEHMER, Introductio in ius publicum universale (Halle ${ }^{2}$ 1726).

Falk BOMSDORF, Prozeßmaximen und Rechtswirklichkeit: Verhandlungs- und Untersuchungsmaxime im deutschen Zivilprozeß. Vom gemeinen Recht bis zur ZPO (= Schriften zum Prozeßrecht 19, Berlin 1971).

Max BRAUBACH, Karl VI., Kaiser, in: NDB, Bd. 11: Kafka-Kleinfercher (Berlin 1977) 211-210.

Wilhelm BRAUNEDER, Österreichische Verfassungsgeschichte (Wien 1992).

Horst BRÜNKER, Der Kriminalist Ernst Ferdinand Klein (1744-1810): Praktiker und Philosoph des aufgeklärten Absolutismus (= Diss., Univ. Bonn 1972).

Emilio BUSSI, Johann Jacob Moser, Pietismus und Reform, in: ZRG KA 54 (1968) 375-382.

Emilio BussI, Zur Geschichte der Machtsprüche, in: Hans Lentze, Peter Putzer (Hgg.), Festschrift für Ernst Carl Hellbling (Salzburg 1971) 51-73.

Heinrich von CoccEJI, Henrici de Coceji Regiae Majest. Boruss. Coniliarii Intimi...Prodromus Justitiae Gentium Sive Exercitationes Duae Quarum Prima Socialitatem Grotianam principium neque essendi neque cognoscendi esse, evincit Secunda veram majestatis originem eruit: Liber Ad Illustriationem Prooemii et Libri primi Tractatus Grotiani De Jure Belli Et Pacis necessarius (Frankfurt 1719).

Ignaz CORNOVA, Unterhaltungen mit jungen Freunden der Vaterlandsgeschichte, Bd. 2: Geschichte Böhmens und seiner Österreichischen Könige von 
Ferdinands II. Regierungsantritt bis zum Schluß des siebzehnten Jahrhunderts (Prag 1800).

Johann Ulrich Freiherr von CRAMER, Systema Processus Imperii seu Superiorum Augustissimorum Tribunalium (Ulm-Frankfurt-Leipzig 1768).

Johann Ulrich Freiherr von CRAMER, Wetzlarische Nebenstunden, worinnen auserlesene, beym Höchstpreißlichen Cammergericht entschiedenen Rechtshändel zur Erweiter- und Erläuterung der teutschen in Gerichten üblichen Rechts-Gelehrsamkeit angewendet werden, 64. Theil (Ulm 1766).

Joachim Georg DARJES, Commentatione de differentiis iurisprudentiae atque politiae, quae vulgo die Policey dicitur (Frankfurt an der Oder 1763)

Walter DEMEL, Preussisches und bayerisches Adelsrecht in der zweiten Hälfte des 18. Jahrhunderts. Ein Vergleich der großen Kodifikationen, in: Maximiliane KRIECHBAUM (Hg.), Festschrift für Sten Gagnér (Ebelsbach am Main 1996) 151-180.

Horst DENZER, Moralphilosophie und Naturrecht bei Samuel Pufendorf. Eine geistes- und wissenschaftsgeschichtliche Untersuchung zur Geburt des Naturrechts aus der praktischen Philosophie (=Münchener Studien zur Politik 22, München 1972).

Bernhard DiESTELKAMP, Reichskammergericht und Rechtsstaatsgedanke, Die Kameraljudikatur gegen die Kabinettsjustiz (=Schriftenreihe Juristische Studiengesellschaft Karlsruhe 210, Heidelberg 1994).

Erich DÖHRING, Geschichte der deutschen Rechtspflege seit 1500 (Berlin 1953).

Horst DreITZEL, Absolutismus und ständische Verfassung in Deutschland. Ein Beitrag zur Kontinuität und Diskontinuität der Politischen Theorie in der frühen Neuzeit (= Veröffentlichungen des Instituts für Europäische Geschichte Mainz, Abteilung für Universalgeschichte, Beiheft 24, Mainz 1992).

Horst DREITZEL, Monarchiebegriffe in der Fürstengesellschaft. Semantik und Theorie der Einherrschaft in Deutschland von der Reformation bis zum Vormärz, 2 Bde. (Köln-Weimar-Wien 1991).

Wilhelm EbeL, Der Göttinger Professor Johann Stephan Pütter aus Iserlohn (= Göttinger rechtswissenschaftliche Studien 95, Göttingen 1975).

Anton Wilhelm ERTEL, Neu-eröffnete Schau-Bühne von dem Fürsten-Recht: Auf welcher Durch hundert auserlesene Politische und Juridische Quaestiones, die vortrefflichste Materien von dem Gewalt, Authorität und Praerogativen derer Fürsten untersucht [...] revolviret werden (Nürnberg 1702).
Hans FENSKe, Gewaltenteilung, in: Otto BRUNNER, Werner CONZE, Reinhart KoselleCK (Hgg.), Geschichtliche Grundbegriffe, Lexikon zur politischsozialen Sprache in Deutschland, Bd. 2 (Stuttgart 1975) 923-958.

Vanda FIORILlO, Das Doppelgesicht der Macht: Zwangsapparat oder Wertordnung? Die Antwort Ernst Ferdinand Kleins, in: Der Staat 38 (1999) 195-219.

Vanda FIORILlo (Hg.), Samuel Pufendorf, filosofo del diritto e della politica: atti del convegno internazionale, Milano, 11-12 novembre 1994 (=Seminari giuridici. Istituto Italiano per gli Studi Filosofici 7, Napoli 1996).

Johann Ernst von FLÖRCKE, Erörterung der Rechtsfrage: $\mathrm{Ob}$ und wie ferne Policey-Sachen vor die Justiz-Collegia gehören, und im selbigen gerichtlichen Processe und gewöhnliche Rechts-Mittel wider die darinnen ertheilte Bescheide und Urtheile statt haben? (Halle 1760).

Werner Frauendienst, Christian Wolff als Staatsdenker (= Historische Studien 171, Berlin 1927, ND Vaduz 1965).

Ferdinand FRENSDORFF, Strube: David Georg St., in: ADB, Bd. 36: Steinmetz-Stürenburg (Leipzig 1893) 635-639.

Bodo GeYER, Samuel Pufendorf und seine Wirkungen bis auf die heutige Zeit (Baden-Baden 1996).

Otto von GIERKE, Johannes Althusius und die Entwicklung der naturrechtlichen Staatstheorien. Zugleich ein Beitrag zur Geschichte der Rechtssystematik (= Untersuchungen zur deutschen Staatsund Rechtsgeschichte NF 7, Breslau 1929, ND Aalen 1968).

Nicolaus Thaddäus von GÖNNER, Commentar über das Königl. baierische Gesetz vom 22. Juli 1819 (Erlangen 1820).

Nicolaus Thaddäus von GöNNER, Teutsches Staatsrecht (Landshut 1804).

Nicolaus Thaddäus von GÖNNER, Handbuch des deutschen gemeinen Processes. In einer ausführlichen Erörterung seiner wichtigsten Gegenstände, Teil I (Erlangen ${ }^{2}$ 1804).

Simone GoYARD-FABRE, Pufendorf et le droit naturel (Paris 1994).

Karl Friedrich HÄBERLIN, Handbuch des Teutschen Staatsrechts nach dem System des Herrn Geheimen Justizrath Pütter, Bd. 2 (Frankfurt-Leipzig 1794).

Werner HARTIG, Die Reform der prozeßleitenden Grundsätze im bayerischen Zivilprozeßrecht (Erkenntnisverfahren) von der Zeit Kreittmayrs bis 
zum Ende der Partikulargesetzgebung (jur. Diss, Univ. Bonn 1968).

Eckhart HellmutH, Naturrechtsphilosophie und bürokratischer Werthorizont: Studien zur preußischen Geistes- und Sozialgeschichte des 18. Jahrhunderts (=Veröffentlichungen des Max-PlanckInstituts für Geschichte 78, Göttingen 1985).

Eckhart Hellmuth, Noch einmal: Freiheit und Eigentum, Zum politisch-gesellschaftlichen Bewußtsein der Landrechtsautoren Carl Gottlieb Suarez und Ernst Ferdinand Klein, in: Günther BIRTSCH, Dietmar WilloweIT (Hgg.), Reformabsolutismus und ständische Gesellschaft (= Forschungen zur brandenburgischen und preussischen Geschichte, Beiheft 3, Berlin 1998) 63-89.

Frank HerdmanN, Montesquieurezeption in Deutschland im 18. und beginnenden 19. Jahrhundert (= Philosophische Texte und Studien 25, Hildesheim-Zürich-New York 1990).

Franz HerRe, Prinz Eugen. Europas heimlicher Herrscher (Stuttgart 1997).

Friedrich Georg von HERTLEIN, Juridisch-Politischer Versuch über die Wesentlichen Rechte der Majestät, nach den Grundsätzen des allgemeinen Staatsrechts (Diss., Univ. Würzburg 1787).

Rudolf HOFFMANN, Die staatsphilosophischen Anschauungen Christian Wolffs mit besonderer Berücksichtigung seiner naturrechtlichen Theorien (Diss., Univ. Leipzig 1916).

Rudolf HOKE, Österreichische und deutsche Rechtsgeschichte (Wien-Köln-Weimar 1992).

Rudolf HOKE, Ilse REITER, Quellensammlung zur österreichischen und deutschen Rechtsgeschichte, vornehmlich für den Studiengebrauch (WienKöln-Weimar 1993).

Heinz HolzHAUER, Gönner, Nicolaus Thaddäus von, in: $\mathrm{HRG}^{1}$, Bd. 1: Aachen-Haussuchung (Berlin 1971) 1752-1755.

Heinz HolzHAUER, Klein, Ernst Ferdinand, in: HRG ${ }^{1}$, Bd. 2: Haustür-Lippe (Berlin 1978) 866-869.

Werner HÜLLE, Das Supplikenwesen in Rechtssachen. Anlageplan für eine Dissertation, in: ZRG GA 90 (1973) 194-212.

Joachim H. JÄCK, Nicolaus Thaddäus Gönners Biographie (Erlangen 1813).

Johann Heinrich Gottlob von JUSTI, Die Natur und das Wesen der Staaten, als die Grundwissenschaft der Staatskunst, der Policey, und aller Regierungswissenschaften, desgleichen als die Quelle aller Gesetze (Berlin-Stettin-Leipzig 1760).

Herbert KALB, Studien zur Summa Stephans von Tournai: ein Beitrag zur kanonistischen Wissenschaftsgeschichte des späten 12. Jahrhunderts
(= Forschungen zur Rechts- und Kulturgeschichte 12, Innsbruck 1983).

Michael KLEENSANG, Das Konzept der bürgerlichen Gesellschaft bei Ernst Ferdinand Klein: Einstellungen zu Naturrecht, Eigentum, Staat und Gesetzgebung in Preußen 1780-1810 (=Studien zur europäischen Rechtsgeschichte 108, Frankfurt am Main 1998).

Michael KLEENSANG, Ernst Ferdinand Klein: ein preuBischer Jurist der Spätaufklärung (Dipl.-Arb., Univ. Erlangen, Nürnberg 1990).

Ernst Ferdinand KLEIN, Beurtheilung der Kritik über das willkührliche Verfahren des Kaisers in Criminalfällen, in: Annalen der Gesetzgebung und Rechtsgelehrsamkeit in den Preussischen Staaten 1 (1788) 391.

Ernst Ferdinand KLEIN, Grundsätze der natürlichen Rechtswissenschaft nebst einer Geschichte derselben (Halle 1797).

Diethelm KLIPPEL, Das Privileg im deutschen Naturrecht des 18. und 19. Jahrhunderts, in: Barbara Dölemeyer, Heiz Mohnhaupt (Hgg.), Das Privileg im europäischen Vergleich, Bd. 1 (Frankfurt am Main 1997) 329-345.

Diethelm KLIPPEL, Politische Freiheit und Freiheitsrechte im deutschen Naturrecht des 18. Jahrhunderts (= Rechts- und Staatswissenschaftliche Veröffentlichungen der Görres-Gesellschaft 23, Paderborn 1976).

Johann Ludwig KLÜBER, Öffentliches Recht des Teutschen Bundes und der Bundesstaaten, 2 Abtheilungen enthaltend das Staatsrecht Teutscher Bundesstaaten (Frankfurt ${ }^{4} 1840$ ).

Kurt KLuXEN, Die Herkunft der Lehre von der Gewaltentrennung, in: Josef ENGEL, Hans M. KLINKENBERG (Hgg.), Aus Mittelalter und Neuzeit. Festschrift für Gerhard Kallen (Bonn 1957) 219-236.

Johann Baptist KOCH, Nikolaus Thaddäus von Gönners Staatslehre. Eine rechtshistorische Studie (= Staats- und völkerrechtliche Abhandlungen 4, 1, Leipzig 1902).

Michael KотULLA, Deutsche Verfassungsgeschichte. Vom Alten Reich bis Weimar (1495 bis 1934) (Heidelberg 2008).

Franz KREITMAIR, Die staatsrechtlichen Grundlehren des Kurfürstlich Bayerischen Geheimen Rats ViceKanzler Wigulaeus Xaverius Aloysius Freiherrn von Kreittmayr (jur. Diss., Univ. München 1952).

Wigulaeus Freyherr von KREITTMAYR, Grundriß des Allgemeinen, Deutsch- und Bayrischen Staatsrechtes, Erster Theil: Von dem allgemeinen Staatsrechte (München-Leipzig 1789). 
Friedrich Wilhelm KREMzOW, Friedrich Tezner. Ein Beitrag zur Geschichte der österreichischen Verwaltungswissenschaft, in: Acta universitatum 1 (1971) 23-41.

Adolf LAufs, Johann Jacob Moser, in: Michael StolLEIS (Hg.), Staatsdenker im 17. und 18. Jahrhundert (Frankfurt am Main 21987) 284-293.

Pierre LAURENT, Pufendorf et la loi naturelle (Paris 1982).

Friedrich LEHNE, Zur Geschichte der Verwaltungsstreitsache in Österreich, in: Wilfried DORAZIL, Bruno SCHIMETSCHEK, Friedrich LEHNE (Hgg.), 90 Jahre Verwaltungsgerichtsbarkeit in Österreich (Wien 1966) 26.

Karl Freiherr von LEMAYER, Der Begriff des Rechtsschutzes im öffentlichen Recht (Verwaltungsgerichtsbarkeit) im Zusammenhange der Wandlungen der Staatsauffassung betrachtet. Festschrift aus Anlass der Feier des 25-jährigen Bestandes des österreichischen Verwaltungsgerichtshofes (Wien 1902).

Miriam LEVY, Governance and grievance. Habsburg Policy and Italian Tyrol in the Eighteenth Century (USA 1988).

Johann Ludwig Friedrich, Freiherr von LiEBENSTEIN, Abhandlung von Cammer- und Justiz-Collegien und ihrem Verhältnis sowohl gegeneinander als den ganzen Staat (Tübingen 1770).

Christoph LINK, Johann Stephan Pütter, in: Michael STOLLEIS (Hg.), Staatsdenker im 17. und 18. Jahrhundert (Frankfurt am Main 21987) 310-331.

Edgar LÖNING, Gerichte und Verwaltungsbehörden in Brandenburg-Preußen. Zweiter Artikel, in: Verwaltungsarchiv, Zeitschrift für Verwaltungsrecht und Verwaltungsgerichtsbarkeit 2 (1894) 437.

Anna-Dorothea LUDEWIG, Zwischen Czernowitz und Berlin. Deutsch-jüdische Identitätskonstruktionen im Leben und Werk von Karl Emil Franzos (18471904) (= Haskala 37, Hildesheim u.a. 2008).

Klaus LUIG, Die Pflichtenlehre des Privatrechts in der Naturrechtsphilosophie Christian Wolffs, in: Okko BEHRENDS (Hg.), Libertas. Grundrechtliche und rechtsstaatliche Gewährungen in Antike und Gegenwart. Symposium aus Anlaß des 80. Geburtstags von Franz Wieacker (Ebelsbach 1991) 209_ 261.

M. Friedrich von MAASBURG, Geschichte der obersten Justizstelle in Wien (1749-1848), größtentheils nach amtlichen Quellen bearbeitet (Prag 1879).

Ludwig Gottfried MADIHN, Grundsätze des Naturrechts zum Gebrauch seiner Vorlesungen, 2. Teil: Hypothetisches Naturrecht (Frankfurt an der Ode 1796).
Karl Anton Freiherr von MARTINI, Allgemeines Recht der Staaten (Wien 1788).

Hans MAIER, Die ältere deutsche Staats- und Verwaltungslehre (München 21980).

Heinrich MARX, Die juristische Methode der Rechtsfindung aus der Natur der Sache bei den Göttinger Germanisten Johann Stephan Pütter und Justus Friedrich Runde (iur. Diss., Univ. Göttingen 1967).

Erwin MATSCH, Der Auswärtige Dienst von Österreich(-Ungarn) 1720-1920 (Wien-Köln-Graz 1986).

Johann Georg MegERLE VON MÜHLFELD, Ursprüngliche Errichtung der k.k. obersten Justizstelle, des k.k. Appellations- und Criminal-Obergerichtes in Österreich ob und unter der Enns, des k.k. n.ö. Landrechtes und des k.k.n.ö. Mercantil- und Wechselgerichtes nebst der Reihenfolge aller diesen Gerichts-Behörden vorgestandenen Präsidenten (Wien 1831).

Johann Georg Meusel (Hg.), Lexikon der vom Jahr 1750 bis 1800 verstorbenen teutschen Schriftsteller, Bd. 13 (Leipzig 1813, ND. Hildesheim 1968).

Robert von MoHL, Geschichte der Literatur der Staatswissenschaft in Monographien dargestellt, Bd. 2 (Erlangen 1855, ND. Graz 1960).

Heinz MohnHaupt, Zu Einfluß, Wirkung und Funktion von deutschen Übersetzungen französischer Schriften in Deutschland: Bodin, Montesquieu und Sieyes, in: Jean-François KERvÉGAN, Heinz MoHnHAUPT (Hgg.), Wechselseitige Beeinflussungen und Rezeptionen von Recht und Philosophie in Deutschland und Frankreich. Drittes deutschfranzösisches Symposion vom 16. bis 18. September 1999 in La Bussière/Dijon (Frankfurt am Main 2001) 1-41.

Charles-Louis de Secondat, Baron de la Brède et de Montesquieu, De l'Esprit des Lois (Paris 1833).

Johann Jacob Moser, Johann Jacob Mosers Abhandlung Von Kayserlichen Macht-Sprüchen In RechtsStaats- und Gemischten Sachen (Franckfurt am Mayn 1750).

Sibylle MÜLLER, Gibt es Menschenrechte bei Samuel Pufendorf? (= Rechtshistorische Reihe 231, Frankfurt am Main u.a. 2000).

Ulrike MÜßIG, Recht und Justizhoheit: Der gesetzliche Richter im historischen Vergleich von der Kanonistik bis zur Menschenrechtskonvention, unter besonderer Berücksichtigung der Rechtsentwicklung in Deutschland, England und Frankreich (= Schriften zur Europäischen Rechts- und Verfassungsgeschichte 44, Berlin 22009).

Ulrike MÜßIG, Summum ius, summum iniuria. Zur Korrekturbedürftigkeit des strengen Rechts in 
deutschen und englischen Rechtsquellen, in: DiEs. (Hg.), Ungerechtes Recht (Tübingen 2013) 23-65.

Alois NiederstätTER, Die Herrschaft Österreich. Fürst und Land im Spätmittelalter (= Österreichische Geschichte 1278-1411, Wien 2001).

Regina OGOREK, Das Machtspruchmysterium, in: Rechtshistorisches Journal 3 (1984) 82-107.

Werner OGRIS, Kabinettsjustiz, in: HRG ${ }^{1}$, Bd. 2: Haustür-Lippe (Berlin 1978) 515-518.

Werner OGRIS, Machtspruch, in: $\mathrm{HRG}^{1}$, Bd. 3: ListProtonator (Berlin 1984) 126-128.

Werner OGRIS, Staats- und Rechtsreformen, in: Walter KOSCHATZKy (Hg.), Maria Theresia und ihre Zeit. Eine Darstellung der Epoche von 1740-1780 aus Anlaß der 200. Wiederkehr des Todestages der Kaiserin (Wien-Salzburg 1979) 56-66.

Thomas OlECHOWSKI, Die Entwicklung allgemeiner Grundsätze des Verwaltungsverfahrens, in: Michael HoloubeK, Michael LANG (Hgg.), Allgemeine Grundsätze des Verwaltungs- und Abgabenverfahrens (Wien 2006) 13-40.

Thomas OleCHOWSKI, Der österreichische Verwaltungsgerichtshof. Geschichte der Verwaltungsgerichtsbarkeit in Österreich - das Palais der ehemaligen Böhmisch-Österreichischen Hofkanzlei (Wien 2001).

Louis PAHLOW, Justiz und Verwaltung. Zur Theorie der Gewaltenteilung im 18. und 19. Jahrhundert (= Naturrecht und Rechtsphilosophie in der Neuzeit 7, Goldbach 2000).

Fiammetta PALladini, Gerald HaRTung (Hgg.), Samuel Pufendorf und die europäische Frühaufklärung. Werk und Einfluß eines deutschen Bürgers der Gelehrtenrepublik nach 300 Jahren (16941994) (Berlin 1996).

Philipp Joseph PANDIN DE JARIGES, Réflexions philosophiques et historiques, d'un jurisconsulte, adressées à son ami à Turin sur l'ordre de la procedure, et sur les décisions arbitraires et immédiates du Souverain (Berlin 1765).

Günther PLATHNER, Der Kampf um die richterliche Unabhängigkeit bis zum Jahre 1848, unter besonderer Berücksichtigung Preußens. Eine dogmengeschichtliche Untersuchung (= Abhandlungen aus dem Staats- und Verwaltungsrecht mit Einschluß des Völkerrechts 51, Breslau 1935).

Walter POHL, Karl VocelKA, Die Habsburger. Eine europäische Familiengeschichte (Wien-Graz-Köln 1992).

Volker PRESS, Calvinismus und Territorialstaat. Regierung und Zentralbehörden der Kurpfalz 15591614 (=Kieler historische Studien 7, Stuttgart 1970).
Christian PROMITZER, Die merkwürdige Flucht eines Jesuitenzöglings im Jahre 1735, in: Kurt MüHLBERGER, Thomas MAISEL (Hgg.), Aspekte der Bildungs- und Universitätsgeschichte - 16. bis 19. Jahrhundert (= Schriften des Archivs der Universität Wien 7, Wien 1993) 271-303.

Wolfgang Heinrich PUCHTA, Die Landgerichte in Bayern und ihre Reform, mit vergleichender Rücksicht auf das deutsche Gerichtsämterwesen der frühern Zeit (Erlangen 1834).

Wolfgang Heinrich PUCHTA, Über die Grenzen des Richteramtes in bürgerlichen Rechtssachen (Nürnberg 1819).

Johann Stephan PÜTTER, Beyträge zum Teutschen Staats- und Fürsten-Rechte, 1. Theil (Göttingen 1777).

Johann Stephan PÜTTER, Anleitung zum Teutschen Staatsrechte (Institutiones iuris Publici), Bd. 2 (Bayreuth 1793).

Johann Stephan PÜTTER, Elementa Iuris Germanici Privati Hodierni in usum auditorum (Göttingen 1748).

Johann Stephan PÜTTER, Opuscula rem iudiciariam imperii illustrantia (Göttingen 1766).

Samuel von PUfENDORF, De jure naturae et gentium libri octo, cum [...] commentariis [...] Jo. Nicolai Hertii [...] Rec. et animadversionibus ill. Gottfridus Mascovius (Francofurti 1744).

Jürgen REGGE, Kabinettsjustiz in BrandenburgPreußen. Eine Studie zur Geschichte des landesherrlichen Bestätigungsrechts in der Strafrechtspflege des 17. und 18. Jahrhunderts (=Strafrechtliche Abhandlungen NF 30, Berlin 1977).

Johann August REICHARDT, Selecta de iure statuum provincialium concurrente circa legislatoriam potestatem, quae praeside [...] submittet Christoph Christianus Ludovicus Hoenninger (Ienae 1769).

Helmut ReINALTER, Joseph II. Reformer auf dem Kaiserthron (München 2011).

Johann Baptist REINGRUBER, Abhandlungen über dunkle Civil-Gesetzesstellen mit der Biographie des Freiherrn von Kreitmayr und einer chronologischen Darstellung des baierischen KriminalInquisitionsprocesses nach dem Texte des Gesetzbuches (Landshut 1814).

Sabrina-Simone RENZ, Johann Jacob Mosers staatsrechtlich-politische Vorstellungen (= Spektrum Politikwissenschaft 2, Würzburg 1998).

Eduard RosentHAL, Die Behördenorganisation Kaiser Ferdinands I. - Das Vorbild der Verwaltungsorganisation in den deutschen Territorien. Ein Beitrag zur Geschichte des Verwaltungsrechts, nach archivalischen Quellen (Wien 1887). 
Gotthilf Sebastian RÖTGER, Nekrolog für Freunde deutscher Literatur, Bd 4 (Helmstadt 1799).

Reinhard RÜRUP, Johann Jacob Moser: Pietismus und Reform (Wiesbaden 1965).

Kari SAASTAMOINEN, The morality of the fallen man. Samuel Pufendorf on natural law (= Studia historica 52, Helsinki 1995).

Heinrich Gottfried ScHEIDEMANTEL, Das allgemeine Staatsrecht überhaupt und nach der Regierungsform (Jena 1775, ND Königsstein 1979).

Heinrich Gottfried ScHEIDEMANTEL, Das Staatsrecht nach der Vernunft und den Sitten der vornehmsten Völker betrachtet, 3 Bde. (Jena 1770-1773).

Josef SCHENK, Der österreichische Richter und Gelehrte Friedrich Tezner, in: Österreichisches Verwaltungsblatt 6; Beilage zur „Wiener Zeitung“ Nr. 7 v. 17. 7. 1935, 185.

Matthäus Joseph ScHICK, Tractatus Iuris Publici de Illicita Instantiarum Multiplicatione et in Specie. Von der Kabinets-Instanz (Giessae ${ }^{1} 1788$ ).

Theodor Schieder, Fritz WAGNER (Hgg.), Handbuch der europäischen Geschichte, Bd.4: Europa im Zeitalter des Absolutismus und der Aufklärung (Stuttgart 1968).

Theodor SCHIEDER, Josef ENGEL (Hgg.), Handbuch der europäischen Geschichte, Bd.3: Die Entstehung des neuzeitlichen Europa (Stuttgart 1971).

Anton ScHINDLING, Walter ZIEGLER (Hgg.), Die Kaiser der Neuzeit 1519-1918. Heiliges Römisches Reich, Österreich, Deutschland (München 1990).

Anton Schindling, Leopold I., in: Ders., Ziegler, Kaiser der Neuzeit 168-185.

Theodor von ScHMALZ, Das natürliche Staatsrecht (Königsberg 21804).

Theodor von SchMALZ, Das teutsche Staats-Recht. Ein Handbuch zum Gebrauche academischer Vorlesungen (Berlin 1825).

Theodor von ScHMALZ, Handbuch der Rechtsphilosophie (Halle 1807, ND Aalen 1970).

Eberhard SCHMIDT, Rechtssprüche und Machtsprüche der preußischen Könige des 18. Jahrhunderts (= Berichte über die Verhandlungen der Sächsischen Akademie der Wissenschaften zu Leipzig, Phil.-hist. Kl. 95/3, Leipzig 1943).

Hans SCHMIDT, Karl VI. (1711-1740), in: SCHINDLING, ZIEGLER, Kaiser der Neuzeit 200-214.

Hans-Peter SCHNEIDER, Die wissenschaftlichen Beziehungen zwischen Leibniz und den beiden Cocceji, in: Hans THIEME (Hg.), Arbeitstagung Humanismus und Naturrecht in Berlin - Brandenburg Preußen (Berlin-New York 1979) 90-102.

Werner SCHNEIDERS (Hg.), Christian Wolff 1679-1754. Interpretationen $\mathrm{zu}$ seiner Philosophie und deren
Wirkung (= Studien zum achtzehnten Jahrhundert 4, Hamburg 1983).

Erwin SснÖMBS, Das Staatsrecht Johann Jakob Mosers (1701-1785). Zur Entstehung des historischen Positivismus in der deutschen Reichspublizistik des 18. Jahrhunderts (= Schriften zur Verfassungsgeschichte 8, Berlin 1968).

Jan SCHRÖDER, Wissenschaftstheorie und Lehre der "praktischen Jurisprudenz" auf deutschen Universitäten an der Wende zum 19. Jahrhundert (= Ius commune. Sonderhefte, Texte und Monographien 11, Frankfurt am Main 1979).

Nikolaus SCHWÄRLER, Friedrich Tezner, 1856-1925, in: Wilhelm BRAUNEDER (Hg.), Juristen in Österreich 1200-1980 (Wien 1987) 242-247.

Veit Ludwig von SECKENDORFF, Teutscher FürstenStaat. Samt des sel. Herrn Autors Zugabe sonderbarer und wichtiger Materien, verbessert und mit Anmerkungen, Summarien und Register versehen v. Andreas Simson von Biechling (Jena 1737).

Ulrike SEIF (= MÜßIG), Recht und Gerechtigkeit: Die Garantie des gesetzlichen Richters und die Gewaltenteilungskonzeptionen des 17.-19. Jahrhunderts, in: Der Staat 42 (2003) 110-140.

Ulrike SEIF (= MÜßIG), Der mißverstandene Montesquieu. Gewaltenbalance, nicht Gewaltentrennung, in: ZNR 22 (2000) 149-166.

James SHEEHAN, German History 1770-1866 (Oxford 1989, ND 1994).

Philipp Jakob SIEBENPFEIFFER, Die Gerichtsverfassung des Rheinkreises, in: Rheinbayern 1 (1830) 48-58.

Jacob Gottlieb SIEBERS, Abhandlung von der Macht der Reichsstände und Gerichtsherrn Selbst Recht zu sprechen (Göttingen 1773).

Tibor SIMÁNYI, Er schuf das Reich. Ferdinand von Habsburg (Wien-München 1987).

Emanuel STIPPERGER, Freiheit und Institution bei Christian Wolff (1679-1754). Zum Grundrechtsdenken der deutschen Hochaufklärung (=Europäische Hochschulschriften Reihe 3, Geschichte und ihre Hilfswissenschaften 241, Frankfurt am Main u.a. 1984).

Michael STOLLEIS, Geschichte des öffentlichen Rechts in Deutschland, Bd. 1: 1600-1800 (München 1988).

David Georg STRUBEN, Gründlicher Unterricht von Regierungs- und Justizsachen; worin untersucht wird: Welche Geschäfte ihrer Natur und Eigenschaften nach vor die Regierungs- oder JustizCollegia gehören (1788) beigeheftet bei: Rechtliche Bedenken, Fünfter Theil (Darmstadt 1788).

David Georg StRUBEN, Nebenstunden, 5. Theil (Hannover 1757). 
David Georg StRuben, Nebenstunden, 3. Theil (Hannover 1761).

Herbert STUPP, Mos geometricus oder Prudentia als Denkform der Jurisprudenz. Eine Untersuchung an Hand der methodologischen Lehren des Christian Wolff und des Thomas von Aquin (iur. Diss., Univ. Köln 1970).

Johann Baptist SutTINGER, Bernhard WALTHER, Consuetudines austriacae (Norimbergae 1718).

Albert TeichmanN, Klein: Ernst Ferdinand K., in ADB, Bd. 16: Kircher-Kotzebue (Leipzig 1882) 8890.

Friedrich TEZNER, Die landesfürstliche Verwaltungspflege in Österreich. Vom Ausgang des 15. bis zum Ausgang des 18. Jahrhunderts, 2 Hefte (Wien 1898, 1902).

Themistokles Tsatsos, Zur Geschichte und Kritik der Lehre von der Gewaltenteilung (=Sb. der Heidelberger Akademie der Wissenschaften, Phil.-Hist. Klasse 1968, 6, Heidelberg 1968).

Gustav TuRBA (Hg.), Die pragmatische Sanktion. Authentische Texte samt Erläuterungen und Übersetzungen (Wien 1913).

Rudolf VIERHAUS, Montesquieu in Deutschland. Zur Geschichte seiner Wirkung als politischer Schriftsteller im 18. Jahrhundert, in: Ernst-Wolfgang BöCKENFÖRDE (Hg.), Collegium Philosophicum, FS für Joachim Ritter (Basel-Stuttgart 1965) 403-437.

Hans WAGNER, Joesph II., Kaiser, in: NDB, Bd. 10: Hufeland-Kaffsack (Berlin 1974) 617-622.

Mack WALKER, Johann Jacob Moser and the Holy Roman Empire of the German Nation (Chapel Hill 1981).

Friedrich WALTER, Die Österreichische Zentralverwaltung, II. Abteilung, Bd. 1, Halbbd. 2, Teil 2 (Wien 1956).
Adam WANDRUSZKA, Maria Theresia und ihre Zeit, in: Werner KoschAtZKY (Hg.), Maria Theresia und ihre Zeit. Eine Darstellung der Epoche 1740-1780 aus Anlaß der 200. Wiederkehr des Todestages der Kaiserin (Wien-Salzburg 1979) 17.

Gerd WeHner, Karl-Georg PfäNDTNER, Franz MACHILEK, Von Bamberg über Ingolstadt und Landshut nach München: Nikolaus Thaddäus Gönner (1764-1827) (Bamberg 1998).

Christoph WEIDLICH, Biographische Nachrichten von den jetzt lebenden Rechtsgelehrten in Deutschland, Theil 2 (Halle 1781).

Hans Welzel, Die Naturrechtslehre Samuel Pufendorfs. Ein Beitrag zur Ideengeschichte des 17. und 18. Jahrhunderts (Berlin 1958).

Dietmar WILLOWEIT, Deutsche Verfassungsgeschichte, Vom Frankenreich bis zur Wiedervereinigung Deutschlands. Ein Studienbuch (= Juristische Kurz-Lehrbücher, München ${ }^{42001) .}$

Heinrich August WINKLER, Der lange Weg nach Westen, Bd. 1: Deutsche Geschichte vom Ende des Alten Reiches bis zum Untergang der Weimarer Republik (München ${ }^{52002) . ~}$

Christian WoLfF, Grundsätze des Natur- und Völkerrechts worin alle Verbindlichkeiten und alle Rechte aus der Natur des Menschen in einem beständigen Zusammenhange hergeleitet werden (Halle 1754, ND Königstein 1980).

Christian WOLFF, Jus naturae methodo scientifica pertractatum, Bd. 8: De Imperio Pvblico Sev Jvre Civitatis, In Qva Omne Jvs Pvblicum Vniversale Demonstratvr Et Verioris Politicae Inconcvssa Fvndamenta Ponvntvr (Frankfurt-Leipzig 1748).

Sven Erik WunNER, Christian Wolff und die Epoche des Naturrechts (Hamburg 1968).

Thomas WÜNSCH, Deutsche und Slawen im Mittelalter. Beziehungen zu Tschechen, Polen, Südslawen und Russen (München 2008). 